\title{
IV Senatus rebellis - die Senatsaristokratie in der Usurpation
}

In den 60 Jahren der Herrschaft des Honorius und Valentinians III. mangelte es keinesfalls an Usurpatoren. Besonders kritisch war die Lage unter Honorius, in dessen Herrschaftszeit die Usurpatoren geradezu wie „Pilze aus der Erde schossen“1. Die Liste der Usurpatoren und Rebellen ist dementsprechend lang und reicht von Eugenius, Priscus Attalus und Johannes in Italien, über Konstantin III. und Jovinus in Gallien, Maximus in Spanien, Gildo und Heraclianus in Africa bis zu weitgehend unbekannten Persönlichkeiten wie Pirrus ${ }^{2}$. Aufmerksamkeit verdienen hier die Usurpationen, in denen dem Senat - oder vielmehr der stadtrömischen Senatsaristokratie - eine zentrale Rolle zufiel.

Zunächst soll aber geklärt werden, wie sich die Kategorisierung der nachfolgenden Fälle, die nicht immer als Usurpationen verstanden werden, begründen lässt. Zunächst handelt es sich um eine Einordnung ex eventu, welche vor allem das Scheitern der Machtkonsolidierung und das gewaltsame Ende vor Augen hat. Damit folgen wir im Grunde der Geschichtsschreibung des Siegers, ${ }^{3}$ die jede in Konkurrenz zum Herrscherhaus der theodosianischen Dynastie ausgeübte Herrschaft als tyrannis ${ }^{4}$ ansah. Gerade in der ersten Hälfte des 5. Jhs. wirkt hierbei besonders stark das dynastische Prinzip, ${ }^{5}$ welches sich sowohl 410/416 als auch 425 durchsetzen konnte und 450 im Osten und 455 im Westen ein entscheidendes Kriterium für den Erfolg bzw. Misserfolg der Herrschaftssukzession darstellte. Gestützt und verteidigt wurde das dynastische Prinzip vor allem durch Konstantinopel. Für die beanspruchte Herrschaft war es so immer auch entscheidend, wie sich der östliche Reichsteil verhielt. In den hier zu untersuchenden Fällen verweigerte der Osten die Anerkennung, so dass auch

1 CLAUSS (1997) 11.

2 DEMANDT 2(2007) 612, führt Pirrus (Pyrrhus?) als Usurpator 428 an; gestützt auf die Annales Ravennatenses, die für diesen „Tyrann“ am 23. Juli 428 die Hinrichtung vermerken. Vgl. auch PFEILSCHIFTER (2013) 19 Anm. 44; SZIDAT (2010) 344 Anm. 1469; PACK (1997) 397.

3 Vgl. Aur. Vict. 33,24.

4 Vgl. z. B. den sog. Tyrannen-Katalog in Oros. 7,42; ferner auch die Auflistung bei Soz. 9,12-16. Die Terminologie wird in der Historiographie des 5. und 6. Jhs. sehr weit gefasst und schlossen mitunter auch die Heermeister/Militärs und rebellische und auch verhasste Amtsträger mit ein. Zum Begriff und seiner Anwendung vgl. SEIBEL (2006) 24-37.

5 Hierzu vgl. aber auch FLAIG 22(2019) 231-234 [1992] und ders. (1997) 20 f. u. 32f., der dieses Prinzip eher negiert. Dagegen vgl. u. a. PFEILSCHIFTER (2013) 14-18 u. 123-137; SZIDAT (2010) 165 - 181; KOLB (2001) 98f.; MARTIN (1997) 48f. und DIEFENBACH (1996) 35-66, hier 37-39. Insbesondere greift hier das Erbcharisma, welches auch junge Kaiser, die keine eigenen Leistungen vollbringen können, zur Herrschaft befähigte; vgl. Ambr. obit. Theod. 6. Der dynastische Gedanke findet auch seinen Ausdruck in der Benutzung des Flaviernamens, der sowohl von den Kaisern der theodosianischen Dynastie, ihren Heermeistern, als auch von Usurpatoren, die eine Anbindung suchten, geführt werden konnte; hierzu vgl. auch DOYLE (2019) 25 und ausführlich CAMERON (1988) 26-33.

Ә OpenAccess. () 2021 Hendrik A. Wagner, publiziert von De Gruyter. (cc))BY-NC-ND Dieses Werk ist lizenziert unter der Creative Commons Attribution-NonCommercial-NoDerivatives 4.0 International Lizenz. 
die fehlende Integration im Herrscherkolleg ${ }^{6}$ und die Missachtung des Vorrangs des senior Augustus wichtige Kriterien darstellen, hier von Usurpatoren zu sprechen, die eben nicht das commune imperium ${ }^{7}$ verkörpern konnten. Daher lassen sich auch Johannes Primicerius ${ }^{8}$ und Petronius Maximus als Usurpatoren einordnen.

Dies bedeutet zwar nicht, dass ein unabhängig von Konstantinopel und dem dynastischen Prinzip erhobener Kaiser nie legitimiert war. Doch musste die Legitimität auf anderen Wegen erreicht werden. Hierbei konnte eine institutionalisierte Legitimität, wie sie der Senat bereitstellen konnte, ${ }^{9}$ hilfreich sein. Die Investitur durch den Senat konnte eine Loyalitätsbindung, wie sie gegenüber einer Dynastie erwuchs, jedoch nicht ersetzen. Dafür aber werden wir gerade im Senat in Rom eine Institution erkennen dürfen, die in ihrer historisch gewachsenen Bedeutung und ihrem Prestige eine Legitimationsquelle darstellte, über welche der Kaiser in Ravenna oder Konstantinopel $^{10}$ nicht verfügte. Wichtiger noch als die Legitimität, die im Grunde jeder Herrscher für sich beanspruchte und die dennoch immer auch abgesprochen werden konnte, ist die Akzeptanz, die gewonnen und aufrechterhalten werden musste. Entscheidend war hierbei die Fähigkeit, die eigene Machtbasis zusammenzuhalten und effektiv zu nutzen. Die von Flaig benannten Akzeptanzgruppen plebs urbana, Heer und Senat ${ }^{11}$ spielen auch hier eine bedeutende Rolle. Im Fall des Attalus und des Petronius Maximus, die ihre Herrschaft von Rom aus ausübten, hat sogar die hauptstädtische Verankerung und damit das stadtrömische Volk wieder eine größere Bedeutung. Für die Spätantike muss die ,klassische‘ Trias allerdings noch um zwei

6 Dies betrifft im Grunde auch Constantius III., der im Osten erst postum, im Zusammenhang mit der Einsetzung Valentinians III., anerkannt wurde. Ebenso Marcian, der zunächst 450 nicht durch den senior Augustus Valentinian III. anerkannt wurde. Marcian wird dann 452 anerkannt (Add. ad. Prosp. Havn. Chron. 490,21). In beiden Fällen soll ein Feldzug in den Osten zumindest geplant gewesen sein; vgl. Olymp. fr. 33 und Ioh. Ant. fr. 201.

7 Oros 7,36,1: commune imperium divisis tantum sedibus. Vgl. auch Claud. III. Cos. Hon. 7. Hierzu vgl. GIRARDET (2008) 83-124, hier 119f. Erfahrbar wurde dies vor allem bei der gemeinsamen Ernennung der Konsuln, an den Insignien der Amtsträger (Bildständer), bei Ehrungen und Bauten im öffentlichen Raum, an der Gesetzgebung und an der Münzprägung.

8 PFEILSCHIFTER (2013) 19, 225 u. 512 benutzt hier sowohl die Bezeichnung (West-)Kaiser als auch Usurpator (die zwei Deutungsvarianten werden auf S. 19 in Anm. 43 genannt).

9 Hier würde der Senat als politische Instanz, die die Herrschaftsbefugnis übertragen (und entziehen) soll, instrumentalisiert werden, was jedoch nichts mit einer freien Wahlentscheidung des Senats zu tun haben muss. FLAIG ${ }^{2}$ (2019) 221f. [1992] und ders. (1997) 16-18. bestreitet allerdings diese Möglichkeit und betrachtet den Senat als „konstitutionell unwichtig“. Zu den Begriffen Legitimität und Akzeptanz vgl. jetzt auch PFEILSCHIFTER (2013) 2-9.

10 Zum Senat in Konstantinopel, der allerdings weder die Tradition und das Prestige noch die Bedeutung und Selbstständigkeit des stadtrömischen Senats besaß, vgl. BEGASS (2018) 35-41; PFEILSCHIFTER (2013) 31f. u. 452-456; SZIDAT (2010) 133-135; SCHLINKERT (1996a) 132-136; LÖHKEN (1982) 104-107 und DAGRON (1974) $122 \mathrm{f}$.

11 FLAIG $^{2}$ (2019) [1992]; zusammenfassend ders. (1997) 16f. Vgl. speziell für die Spätantike PFEILSCHIFTER (2013) 28-38, der hier auch den Klerus als wichtige Akzeptanzgruppe berücksichtigt; in seiner Einteilung: Heer, Volk, Eliten und Klerus. Ferner vgl. auch DIEFENBACH (1996). Hierzu vgl. auch Kap. 2.1. 
weitere Akzeptanzgruppen ergänzt werden: den Hof und den Klerus. ${ }^{12}$ Als Machtbasis kommen aber letztlich nur das Heer, der Senat und der Hof in Frage, mit deren Unterstützung sich militärische, administrative und finanzielle Handlungsräume schaffen ließen.

Der Legitimitätsbegriff soll aber nicht gänzlich negiert werden. Anders als Flaig wird hier die Legitimität als dynamische Größe angesehen, die durch Handlungen geschmälert und gesteigert werden konnte. ${ }^{13}$ Sie muss, gerade wenn sie nicht auf dem dynastischen Prinzip, dem Erbcharisma und ererbten Loyalitätsbindungen aufbaute oder durch die Solidarität der Herrscher ${ }^{14}$ gestützt wurde, fortwährend unter Beweis gestellt werden. Dabei waren die Anerkennung und Zustimmung der Akzeptanzgruppen entscheidend. Eine Besonderheit stellt hierbei dar, dass in den hier zu besprechenden Fällen die Akzeptanz von der Bewältigung einer konkreten Problemstellung abhängig gemacht wurde. Zumeist handelte es sich um militärische Probleme. Hinzu konnten administrative Missstände, religionspolitische Härten und Unsicherheiten in der Herrschersukzession kommen. Hierbei scheint es weniger darum gegangen zu sein, den amtierenden Kaiser zu beseitigen, als vielmehr durch eine erzwungene Erweiterung des Herrscherkollegs ${ }^{15}$ neue Handlungsoptionen zu schaffen. Folglich stehen die neu erhobenen Herrscher stark unter einem Leistungs- und Erfolgsdruck. Sie legitimierten sich letztlich durch den Erfolg ihres Handelns, was gerade dann besonders wirkungsvoll war, wenn der amtierende Kaiser erfolglos oder handlungsunfähig war. Das Handeln der neu erhobenen Kaiser war hierbei erheblich von den Interessen der Akzeptanzgruppen und vor allem von seiner Machtbasis abhängig. Besonders interessant ist hier, welche Bedeutung dem Senat und der stadtrömischen Senatsaristokratie zufiel, zumal Attalus, Johannes Primicerius und Petronius Maximus immer wieder als „Senatskaiser“16 bezeichnet werden.

12 Da in den folgenden Fällen die Quellen keine Auskunft darüber geben, inwiefern sich der stadtrömische Klerus, allen voran der Bischof von Rom, verhielt, wird diese Akzeptanzgruppe keine weitere Berücksichtigung finden können. Zur Bedeutung des Klerus, allerdings für Konstantinopel, vgl. PFEILSCHIFTER (2013) 355-451, der hier aber nicht von einer Akzeptanzgruppe spricht; dagegen LEPPIN (2017) 495, Anm. 44. Vgl. hierzu auch Kap. 2.1.

13 Entgegen FLAIG ${ }^{2}(2019)$ 196-235 [1992]; ders. (1997) 15f. u. 30 f. Hier eher im Verständnis Max Webers: „Legitimitätsglaube“; vgl. WEBER ${ }^{5}(1980)$ 15-19 (i. B. §7 $\alpha$ : kraft Vereinbarung der Interessenten für diese) u. 122-124 (i. B. § 2.3: charismatischer Charakter). Vgl. auch allgemein GOTTER (2008) 173-186, bes. 180; KOLB (2001) 25-27 u. 93-102 und SÜNSKES THOMPSON (1993) 56-70 (allerdings für die Prinzipatszeit mit besonderer Berücksichtigung der plebs urbana).

14 PFEILSCHIFTER (2013) 14-18 verwendet hier den Begriff der „monarchischen Solidarität“.

15 So ist bezeichnend, dass in allen drei Fällen eine Mitherrschaft und Integration im Herrscherkolleg angestrebt war oder zumindest erwogen wurde. Für Attalus: Zos. 6,8,1, wobei dies von Seiten des PPO Jovius abgelehnt worden sein soll. Für Johannes und Petronius Maximus belegen vor allem die Münzlegenden VICTORI-A AVGVSTORVM oder VICTORIA AVGGG, dass an einer gemeinsamen Herrschaft mit dem Kaiser im Osten festgehalten wurde.

16 U. a. MEIER (2019) 473; LÜTKENHAUS (1998) 11; DEMANDT (2013a) 69 [1980]; nachfolgend ders. 2(2007) 331; MAZZARINO (1980) 804f. und HARTKE (1972) 188; kritisch bezüglich der Terminologie SZIDAT (2010) 264 mit Anm. 1058. 


\subsection{Priscus Attalus und das Scheitern senatorischer Politik}

Als Ende 409 Alarich, nachdem die Verhandlungen mit Ravenna gescheitert waren, ${ }^{17}$ erneut vor Rom Stellung bezog, sahen sich die Senatoren, die vergeblich Hilfe und Weisung von Honorius erhofft hatten, zum äußersten getrieben:

Nun wurden die Gesandten Alarichs angenommen, er selbst vor die Stadt gerufen, und, nach seinen Befehlen, erhob man den Attalus, den Stadtpräfekten, auf den kaiserlichen Thron, und legte ihm Purpurmantel und Diadem an. ${ }^{18}$

Nach der Schilderung des Zosimos besteht kein Zweifel, wer hier zum auctor imperii des Attalus wurde. Alarich soll den Senat angewiesen haben, den Stadtpräfekten zum Kaiser zu erheben. Dementsprechend lakonisch fasst dies auch Orosius zusammen:

Was soll ich über den sehr unglücklichen Attalus sagen, [...] der schneller als dies erzählt werden kann, zum Kaiser gemacht, abgesetzt, wieder eingesetzt und im Stich gelassen wurde [...]. ${ }^{19}$

Erstmals meldete Lütkenhaus Zweifel an, ${ }^{20}$ die Rolle Attalus’ nur auf die eines „Marionetten-Kaisers“ ${ }^{\text {“21 }} \mathrm{zu}$ reduzieren, und verwies hierbei explizit auf die Bedeutung des Senats. Gewiss mochte die Blockade Roms, deren Folgen Hunger und Chaos absehbar waren, den Senat zu diesem Schritt getrieben haben, so dass Attalus seine Erhebung unbestreitbar dem Zutun Alarichs zu verdanken hat. Doch ob dies ausschließlich auf einen „Befehl“ des Alarich zurückzuführen ist, lässt sich anzweifeln. Immerhin bestand im Angesicht des erneuten Belagerungszustands auch für den Senat und die stadtrömische Senatsaristokratie Handlungsbedarf. Um aber überhaupt handeln zu können, bedurfte man bis dato des Kaisers, gegen dessen Willen keine Entscheidung gefällt werden konnte. Da dieser jedoch Rom fern war und überdies der Hof keine Anstalten machte, Roms Schutz zu gewährleisten, hatte der Senat allen Grund, sich vom Kaiser im Stich gelassen zu fühlen. Die kaiserliche absentia hatte schon früher in kritischen Situationen immer wieder Usurpationen, gewissermaßen als Mittel zur Selbsthilfe, generiert. ${ }^{22}$ In diesem Fall war es nun aber so, dass nicht wie üblich das

17 Zos. 5,49,1-4 u. 6,6,2.

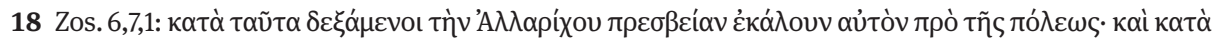

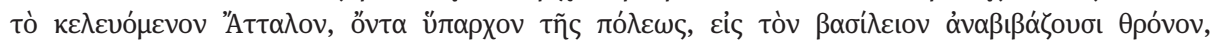

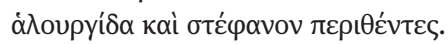

19 Oros. 7,42,7: Quid de infelicissimo Attalo loquar, [...]? In hoc Alaricus imperatore facto infecto refecto ac defecto, citius his omnibus actis paene quam dictis, mimum risit et ludum spectauit imperii [...]. Vgl. auch Soz. 9,8,1; Philost. 12,3 und Olymp. fr. 10 (Blockley).

20 LÜTKENHAUS (1998) 33; nachfolgend auch GOLTZ (2002) 547-572, hier 563-566.

21 So immer noch PFEILSCHIFTER (2013) 484; MEIER/PATZOLD ${ }^{3}$ (2013) 90; SGUAITAMATTI (2012) 109; SZIDAT (2010) 266; CASTRITIUS (2009) 292; SEIBEL (2006) 121; BLECKMANN (2007) 97-110, hier 102; WOLFRAM (2005) 150; BEIER (2002) 398; LEPPIN (1996) 148 Anm. 20; CAMERON (1994) 164.

22 Auch die Usurpation des Konstantin III. 407 lässt sich so verstehen, dass die kaiserliche Präsenz in Britannien und Gallien angesichts der Bedrohungen, der die Rheingrenze und die dortigen Provinzen 
Heer, sondern der Senat sich einen Kaiser kürte. ${ }^{23}$ Es bleibt allerdings zu fragen, wieso die Wahl gerade auf Priscus Attalus fiel. Sicherlich war dieser bereits als Mann der Senatsgesandtschaften am Hof in Erscheinung getreten. Vom Kaiser zu diesem Anlass zum comes sacrarum largitionum ernannt, ${ }^{24}$ hatte Attalus 409 sogar noch die Stadtpräfektur ${ }^{25}$ inne. Damit stand Attalus dem Senat vor und führte wohl auch die Verhandlungen mit Alarich, so dass er zu diesem Zeitpunkt als wichtigster Entscheidungsträger vor Ort fungierte. Dennoch war er weder Konsul gewesen noch Vertreter eines der namhaften Häuser Roms. ${ }^{26}$ Erst durch die jüngsten Entwicklungen war Attalus zum vir inlustris aufgestiegen. Seine rhetorische Begabung und hohe Bildung prädestinierten ihn aber schon zuvor nicht nur für Senatsgesandtschaften, sondern auch für den Kreis jener erlesenen Senatoren um Quintus Aurelius Symmachus, ${ }^{27}$ die sich als pars melior humani generis ${ }^{28}$ verstanden.

Mit der Erhebung des Priscus Attalus und der dadurch zustande kommenden Übereinkunft mit Alarich tritt ein weiterer Akteur in Erscheinung. Dieser Akteur, der zwischen 408 und 410 vorübergehend einen beachtlichen Einfluss auf den ravennatischen Hof und damit auf den Kaiser ausüben konnte, ${ }^{29}$ war der praefectus praetorio

ausgesetzt waren, wieder hergestellt werden sollte; vgl. Zos. 6,3. Zur Konzeptualisierung der Usurpation in der Spätantike vgl. FLAIG 1997, 15-34. Überdies bedurfte auch Alarich eines verlässlichen Verhandlungspartners, den der Kaiser und der Hof in Ravenna zu geben nicht imstande waren. Zum Bemühen um römische Vertragspartner, das ganz im Interesse Alarichs lag, vgl. SZIDAT (2010) 343. 23 Allein Philost. 12,3, lässt ohne Einflussnahme des Alarichs den Senat seine Wahl frei treffen; vgl. zur Stelle BLECKMANN (2007) 100 -103. PASCHOUD (1989) 43, spricht sich hingegen für die Lesung nach Soz. 9,8,1, und Zos. 6,7,1, aus, wonach Alarich dem Senat den Attalus vorschlug; nachfolgend auch SZIDAT (2010) 253. Die Investitur aber oblag letztlich allein dem Senat, wie dies aus Zos. 6,7,1 deutlich

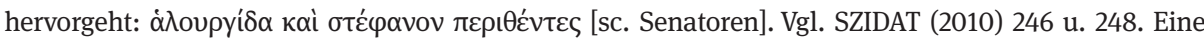
Vorstellung von diesem Vorgang vermittelt SHA. Tac. 6,2f. Die Akklamation und Erhebung vor der Stadt, die sich vor den Truppen des Alarich ereignet (Zos. 6,7,1), ist konsekutiv und erfolgt erst nach Beratung und Wahl im Senat (Zos. 6,6,5). Zur Bedeutung der gotischen Truppen vor Rom als „Wahlversammlung“ vgl. SZIDAT (2010) 245 f. u. 253.

24 Zos. 5,44,1. Hierzu und zur Laufbahn des Attalus insgesamt vgl. DELMAIRE (1989b) 175-178; PLRE 2, 180 f. (Priscus Attalus 2), und ferner SEECK (1921) Sp. 2177-2179.

25 Zos. 6,7,1.

26 Philost. 12,3. Wohl aus dem Osten mit Publius Ampelius (PLRE 1, 56f.; PVR zwischen 370 und 372) übergesiedelt. Dies legt zumindest die Namensgebung des Sohns des Attalus nahe, der den Namen Ampelius erhielt (Zos. 6,12,3); auch PLRE 2, $180 \mathrm{f}$ (Priscus Attalus 2); ferner CHASTAGNOL (1962) $266 \mathrm{f}$. und SEECK (1921) 596.

27 Symm. ep. 7,15-25; 7,54; 7,113 u. 7,114 (zu seiner rhetorischen Begabung). In dieser Zeit schien Attalus sich aus dem öffentlichen Leben auf ein Landgut nahe Roms zurückgezogen $\mathrm{zu}$ haben; vgl. Symm. ep. 7,15, wo es heißt: adde te rusticantium numero et paulisper Catones et Atilios aemulare, quos vomis et stiva ad consulares misit secures [...]; vgl. WYTZES (1977) 70f. Vgl. aktuell JONES (2014) $115 \mathrm{f}$. und CAMERON (2011) 367.

28 Symm. ep. 1,52.

29 Vgl. hierzu am ausführlichsten LÜTKENHAUS (1998) 24-31 und MATTHEWS (1975) 274f. u. 293 299 und BURY (1958) 178-182. 
Jovius $^{30}$. Es handelt sich hierbei um einen Mann, dessen Ränke und inszenierte Wirrungen $^{31}$ schon die antiken Historiker mit Konfusion zur Kenntnis nahmen. ${ }^{32}$ Sein Kurs, der zunächst auf die Verständigung mit Alarich ausgerichtet war ${ }^{33}$ und dann doch wieder dessen unerbittliche Bekämpfung in Schwüren bekräftigte, ${ }^{34}$ konnte nur schwer als geradlinig angesehen werden. Doch dies bedingte das politische Klima am Hof des Honorius. Mit Attalus konnte hingegen Jovius seine ursprünglichen Pläne nun tatsächlich realisieren. ${ }^{35}$ Entsprechend wechselte Jovius, der überdies sogar als „Freund und Gastfreund“ ${ }^{36}$ des Alarich galt, bei der ersten sich ihm bietenden Gelegenheit in das Lager des Attalus. ${ }^{37}$ In welchem Ausmaß Jovius bei der Erhebung des Attalus mitwirkte, lässt sich zwar nicht mehr klären, fest steht aber, dass er unter diesem rasch zum patricius erhoben wurde ${ }^{38}$ und der wichtigste Vermittler ${ }^{39}$ zwischen Alarich und Attalus war.

Einhellige Meinung herrschte bei den nachfolgenden Generationen, die das Scheitern des Attalus deutlich vor Augen hatten, bezüglich seiner Regierungserklärung. Als über alle Maßen prahlerische Rede wurde sie wahrgenommen. In diesem harten Urteil stehen pagane und christliche Autoren zusammen, ${ }^{40}$ und noch Seeck vermerkte harsch, dass Attalus mit seiner Rede „weiter nichts [bewies], als dass sein kindlicher Idealismus den gegebenen Verhältnissen nicht Rechnung zu tragen ver-

30 PLRE 2, 623f.; ausführlich vgl. LÜTKENHAUS (1998) 24-29.

31 Zos. 5,47,1: Jovius soll im Bund mit Allobich (PLRE 2, 61) eine Meuterei der ravennatischen Truppen angezettelt haben, um den Kaiser einzuschüchtern und so ihren Einfluss auf diesen festigen zu können. Vgl. LÜTKENHAUS (1998) 26.

32 Vgl. Die Zosimos-Ausgabe PASCHOUD (1989) 306-309.

33 Zos. 5,48; Soz. 9,7 oder Olymp. fr. 8 (Blockley).

34 Zos. 5,49,4. Dies nachdem die Verhandlungen durch die Entscheidung des Kaisers gescheitert waren.

35 Vgl. LÜTKENHAUS (1998) $27 \mathrm{f}$.

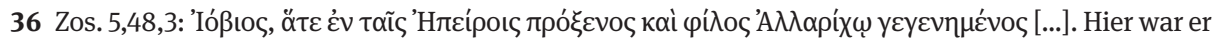
wohl zuvor in Epirus in der Position des PPO Illyriens bereits als Verbindungsmann des Stilicho tätig (Soz. 8,25,3 und 9,4,3). Überdies hatte Jovius schon im Auftrag des Honorius die Verhandlungen mit Alarich geführt; vgl. Soz. 9,7 oder Olmp. fr. 8 (Blockley). Hierzu MATTHEWS (1975) 293f. u. 298.

37 Zos. 6,8,1; Olymp. fr. 10 u. 14 (Blockley); Philost. 12,3. Zuvor scheint er aber noch soweit auf Honorius eingewirkt zu haben, dass dieser eine Teilhabe des Attalus an der kaiserlichen Macht ernsthaft erwogen hatte. In diesem Falle wäre seine Rechnung ebenfalls aufgegangen, denn der Kontrakt, der durch Attalus mit Alarich möglich wurde, hätte weiter bestehen können und hätte überdies auch von Honorius als Mitkaiser akzeptiert werden müssen. Zur fragwürdigen Rolle des Jovius, die bereits die nachfolgenden Geschichtsschreiber nur vage einzuordnen verstanden vgl. PASCHOUD (1989) 306-309 und MATTHEWS (1975) 274f., 293f., $297 \mathrm{f}$.

38 Zos. 6,8,1 weist ihm auch die Stellung des PPO zu, jedoch hatte dieses Amt Lampadius inne

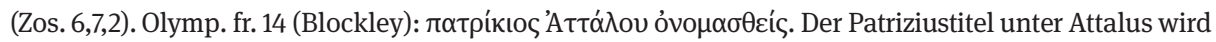
so explizit nur von Olympiodor erwähnt. Hierzu vgl. BURNS (1994) 243; CLOVER (1983) 127-156, hier 141f. und O’FLYNN (1983) 65.

39 Zos. 6,9,5.

40 Olymp. fr. 10,1 (Blockley); Soz. 9,8,2 und Zos. 6,7,4; hierzu LÜTKENHAUS (1998) 32, Anm. 56. 
stand“411. Und so muss es in der Tat am Ende aussehen, wenn Attalus vor dem Senat verkündet, er wolle auch Ägypten und das Ostreich, ${ }^{42}$ ja sogar die ganze Welt unter die Herrschaft der Römer stellen ${ }^{43}$ und dem Senat seine angestammten Rechte ${ }^{44}$ wahren. Doch wie bereits Lütkenhaus vollkommen zu Recht anmerkt, stellt dies ,ein Urteil ex eventu“ ${ }^{45}$ dar, welches den Blick auf die realen Gegebenheiten und das Potenzial, das die Herrschaft des Attalus tatsächlich hatte, verbaut.

Obgleich der Inhalt der Rede des Attalus durch Olympiodor, Sozomenos und Zosimos stark paraphrasiert und drastisch unter dem Topos der Hybris subsumiert wurde, präsentieren sich die Grundgedanken der Regierungserklärung nun auch auf den Münzen des Attalus ${ }^{46}$. Zunächst verzichtet Priscus Attalus zugunsten der älteren, schlichteren Herrschertitulatur P(ius) F(elix) AVG(ustus) ${ }^{47}$ auf die Anrede als Dominus

41 SEECK (1913) 405.

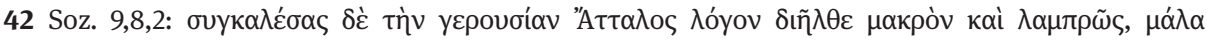

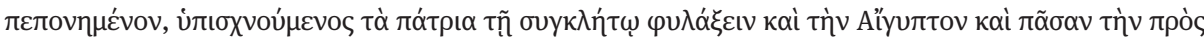

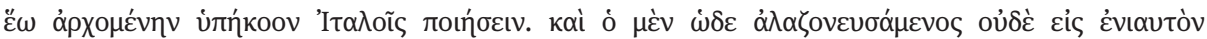

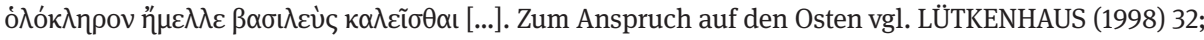
dagegen SZIDAT (2010) 208, Anm. 819: „Keine Maßnahme des Usurpators Attalus belegt, dass er mehr als die Herrschaft im Westen wollte, wenn überhaupt.“ und PASCHOUD (1989) 45, der hierin nur ein ideologisches Programm ohne Realitätsbezug ausmachen wollte; ferner auch BLOCKLEY (1981) 213, Anm. 20: „Attalus’ speech was thoroughly anachronistic.“ Der Erwähnung des Ostens und insbesondere Ägyptens könnte hierbei auch eine historische Reminiszenz sein, die zurückblickend auf den siegreichen Kampf des Octavian gegen Antonius und Cleopatra, den Herrschaftsanspruch Roms und des Westens über den Osten und die Kornkammer Ägypten einforderte. CTh. 7,16,2 (24.4.410), scheint zumindest zu belegen, dass sich der Osten durchaus bedroht fühlte. Gerade ein Übergreifen auf Epirus und Ostillyrien war hierbei nicht unwahrscheinlich, zumal Alarich, Jovius und Valens 2 in dieser Region bereits operiert hatten. BLECKMANN (1997) 591f. betont, dass die Einbeziehung des Ostens durchaus ein realpolitisches Programm darstellte, welches sich so nicht wesentlich von den Ansprüchen des Honorius auf den Osten unterschied.

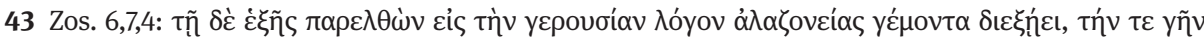

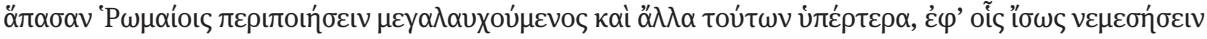

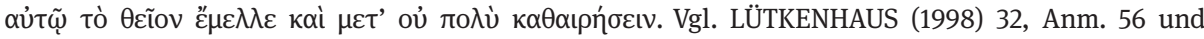
PASCHOUD (1989) 45. Von Zosimos wird die Rede des Attalus wesentlich stärker auf das rhetorisch ausformulierte Leitbild der „Weltherrschaft“ des caput mundi reduziert, welches eher dem traditionellen Herrschaftsanspruch der Römer, gemäß Verg. Aen. 6,847-853: tu regere imperio populos, Romane, memento [...], Rechnung trug.

44 Soz. 9,8,2. Was mit diesen angestammten Rechten konkret gemeint ist, lässt sich aus dem Text nicht erschließen. Möglicherweise beinhaltet dies, wie es so auch Zosimos wiedergab, den römischen Herrschaftsanspruch (Verg. Aen. 6,847-853), der nun wieder durch den Senat vertreten werden sollte, dem das Recht der Kaiserwahl und seine beratende Funktion zurückgegeben wurde, indem der Kaiser fortan im Verbund mit dem Senat regieren sollte.

45 LÜTKENHAUS (1998) 32.

46 Vgl. BRUNI (2015) 43-56 und LÓPEZ SÁNCHEZ (2003) 269-286; ferner CECCONI (2013) 153-155 und GRIERSON/MAYS (1992) $222 \mathrm{f}$.

47 RIC 10, At1: IMP. PRISCVS AT - TALVS P. F. AVG; At2: PRISCVS ATTA - LVS P. F. AVG.; At3: PRISC ATTA - LVS P F AVG. Zur Münzprägung des Priscus Attalus (409/410 u. 414/415) vgl. SAYLES, Ancient Coin Collecting III (2007) 188; BEIER (2002) 398-400 oder VAGI (2000) 548f. 
noster, wie sie zeitgleich sowohl von Honorius und Theodosius II. als auch von dem Usurpator Konstantin III. und dessen $\mathrm{Sohn}^{48}$ in Anspruch genommen wurde. Die Rückseite der Münzen ist zumeist der Herrschaft der Stadtgöttin Roma ${ }^{49}$ verpflichtet, die thronend mit Victoria in der rechten Hand und Zepter in der linken dargestellt wurde, ${ }^{50}$ oder ihren Tempel ${ }^{51}$ zeigt. Bekräftigt wurde dieses Bild mit der von Demandt als „unfreiwillig ironische Devise ${ }^{\text {“52 }}$ ausgelegten Legende VICTORIA - ROMANORVM ${ }^{53}$ und INVICTA RO-MA AETERNA ${ }^{54}$.

Die Grundlage hierfür wurde zumindest insofern gelegt, als dass Attalus sofort daranging, dem Gemeinwesen erfahrene und fähige Beamte voranzustellen. ${ }^{55}$ So wurde Postumius Lampadius zum praefectus praetorio und Marcianus zum praefectus Urbi ernannt. ${ }^{56}$ Es handelt sich hierbei um Personen, die Brown als ,a clique of romantic pagan senators" 57 titulierte. Mit Postumius Lampadius, dem ehemaligen Stadtpräfekten von 403 und $408^{58}$ und Marcianus, der bereits 393/394 als proconsul Africae $^{59}$ amtierte, wurden Beamten berufen, die sich vor allem durch Erfahrung auszeichneten. Sie konnten sowohl angesehene Häuser Roms als auch wichtige Regionen, deren Patrone sie waren, der Einflusssphäre des Attalus hinzugewinnen. Der dritte im Bunde stand dem in nichts nach. Es war der zum Konsul bestimmte Ter-

48 RIC 10, C3: D. N. CONSTAN - TINVS P. F. AVG. Ferner auch dessen Sohn Constans (RIC 10, Cn1: D. N. CONSTA -NS P. F. AVG.), wobei C1 und C2 auch auf die Anrede D(ominus) N(oster) verzichten.

49 Vgl. z. B. RIC 10, 1404. Vgl. auch MATHISEN (2013) 97 f., Fig. 2. Zur Roma-Ideologie vgl. jetzt auch CHAUVOT (2017) 739-774.

50 RIC 10, 1402-1408; 1411; 1412; 1417. Zur Bedeutung der Roma-Idee in der Münzprägung der in Rom erhobenen Usurpatoren vgl. EHLING (2001) 141-158; hier 152f. mit Anm. 64.

51 INVICTA ROMA AETERNA (Multiplum aus Silber; in RIC nicht aufgeführt). Vgl. KANTOROWICZ (ND 1998) 75 f. [1965]; GRABAR (1936) 222, und COHEN (1892) 204f., Nr. 3, 5, 6. Eine mögliche renovatio nach der Plünderung Roms diskutiert LADNER (1959) 250 - 252.

52 DEMANDT ${ }^{2}(2007) 177$.

53 RIC 10, 1409 u. 1410; 1413-1415.

54 RIC 10, $1403-1408$; 1411 u. 1412.

55 Grundlegend CECCONI (2013) 141-162, bes. 156-158 (mit einer Aufstellung aller Amtsträger). Ferner vgl. auch MALLÁ (1983/1984) 47-55.

56 Zos. 6,7,2; Postumius Lampadius 7 (PLRE 2, 656) und Marcianus 14 (PLRE 1, 555 f.). Vgl. CAMERON (2011) 194; MATTHEWS (1975) 295f.; PASCHOUD (1986) 44.

57 BROWN (1972) 190; ähnlich auch PASCHOUD 1986, 44. Dagegen findet die Religionsfrage bei SEIBEL (2006) 119-121 und LÜTKENHAUS (1998) 31-38 keine Beachtung. Vgl. ferner MATTHEWS (1975) 295-300 u. 302-305.

$58 \mathrm{Zu}$ unterscheiden von Lampadius 2 (PLRE 2, 655), der die Stimme gegen die von Stilicho vorgebrachten Geldzahlungen an Alarich erhob (Zos. 5,29,15) und dem PVR von 398 Lampadius 1 (PLRE 2, 654). Vgl. MCEVOY (2013a) 179 Anm. 147; CAMERON (2011) 193 u. 733 f.; ferner auch VON HAEHLING (1978) 315; MATTHEWS (1975) 295f.; CHASTAGNOL (1962) $260 \mathrm{f}$. und MAZZARINO (1942) 353-356 u. 358. 59 Marcianus 14 (PLRE 1, 555f.); Carm. c. pag. 56. Vgl. OLSZANIEC (2013) 187; CAMERON (2011) 194. Vgl. auch MATTHEWS (1970b) 464-479. Eine Identifizierung mit Iulius Agrius Tarrutenius Marcianus (Marcianus 20: PLRE 2, 718f.), dem in CIL 6, 1735, hoch gerühmten Stadtpräfekten, kann nur hypothetisch erfolgen, zumal sich sonst die Schwierigkeit ergeben würde zu erklären, aus welchen Gründen die Stadtpräfektur unter einem Usurpator angeführt werden durfte. Vgl. VON HAEHLING (1978) 404. 
tullus, ${ }^{60}$ der, falls er 358 die Stadtpräfektur ${ }^{61}$ bekleidet haben sollte, in sehr hohem Alter und Ansehen gestanden haben muss. So wurden die zivilen Ämter mit bemerkenswerter Umsicht, ja sogar Weitsicht, nach dem Kriterium der persönlichen und fachlichen Eignung vergeben. Das Heidentum, so muss Brown erwidert werden, war hierbei kein entscheidendes Kriterium. ${ }^{62}$ Lampadius und Marcianus könnten zwar Heiden $^{63}$ gewesen sein, gesichert ist das aber nicht. ${ }^{64}$ Letzterer muss sogar eher als abtrünniger Christ $^{65}$ gelten. Attalus selbst bekannte sich zumindest formal zur arianischen Taufe ${ }^{66}$ und ließ auf seine Münzen auch das Labarum ${ }^{67}$ prägen. Tertullus wird wohl, entgegen der verbreiteten Lesung nach Orosius, ${ }^{68}$ doch als Christ gelten dürfen ${ }^{69}$ und auch der Überläufer Jovius ${ }^{70}$ war vermutlich ein Christ. Insgesamt wird daher Sozomenos nicht ganz unrecht damit gehabt haben, dass unter Attalus Christen und

60 Zos. 6,7,4 und Oros. 7,42,8.

61 Tertullus 1 (PLRE 2, 1059), Tertullus 2 (PLRE 1, 882f.). Vgl. CAMERON (2011) 66 u. 165, identifiziert Tertullus mit dem gleichnamigen PVR von 358-361 (Amm. 19,10: während einer Hungersnot in Rom), was aber bedeuten würde, dass dieser die 80 Jahre fast erreicht oder bereits überschritten hätte, als er 410 das Konsulat antrat (womöglich das älteste Senatsmitglied, das als dienstältester PVR vielleicht auch caput senatus war).

62 Noch zu Beginn der Diskussion Ende des 19. Jh. schrieb SCHULTZE (1887) 373: „Das neue Kaisertum lebte nicht lange genug, um die religiöse Frage mit Ernst in Erwägung zu ziehen; es gab den ,Altgläubigen“ nur Stücke, nichts Ganzes."

63 Vgl. VON HAEHLING (1978) 315f. u. $404 \mathrm{f}$.

64 Vgl. CAMERON (2011) 193f. und JANSSEN (2002) 164.

65 Carm. c. pag. 78 ff., bes. 85 f.: Hiernach soll Marcianus vom Christentum abgefallen sein, um ein höheres Amt zu erlangen (wohl in der Zeit unter Eugenius). Vgl. CAMERON (2011) 194.

66 Vgl. VON HAEHLING (1978) 403f. Zur Taufe durch den arianischen Bischof Sigesarius Soz. 9,9,1; Philost. 12,3; Zos. 6,7,3f. Vgl. ferner SZIDAT (2010) 261 und PASCHOUD (1989) 45f. u. 126. SZIDAT (2010) 261 u. 376, irrt wohl in seiner Annahme nicht, dass ein akzeptabler Kaiser nach 337 Christ (i. B. ein rechtgläubiger Christ) sein musste; so bereits SCHULTZE (1887) 372. Attalus hingegen konnte mit seiner ursprünglich heidnischen Gesinnung und dem Bekenntnis zum arianischen Christentum sowohl vor den ,Altgläubigen“ als auch den gotischen foederati akzeptabel erscheinen und sich überdies gegenüber dem streng orthodoxen Kaisertum abgrenzen, was ihm auch die Sympathien der unterdrückten christlichen Sektierer (Donatisten, Pelagianisten, Originisten etc.) in Ost und West versprach.

67 RIC 10, 1401 u. 1416.

68 Oros. 7,42,8: loquar vobis, patres conscripti, consul et pontifex, quorum alterum teneo, alterum spero [...]. Zos. 6,7,4 hingegen äußert sich nicht bezüglich der Glaubenszugehörigkeit des Tertullus; vgl. hier auch CECCONI (2013) 159.

69 CAMERON (2011) 194: „We have just seen that Tertullus was a Christian“; bes. 165 in Auseinandersetzung mit der Darstellung des Orosius. Dagegen SGUAITAMATTI (2012) 109f.; SALZMAN 2(2004) 65 und VON HAEHLING (1978) 403: „Der Usurpator berief profilierte Heiden in die höchsten Zivilämter.“

70 Vgl.VON HAEHLING (1978) 314. Dies trifft umso mehr zu, sollte Jovius 3 (PLRE 2, 623f.) identisch mit Jovius 2 (PLRE 2, 622f.) sein, der 399 als comes Africae an der Zerstörung heidnischer Tempel beteiligt war (Aug. Civ. Dei 18,54). Vgl. auch JANSSEN (2002) 164, Anm. 43, und MAZZARINO (1942) $394 \mathrm{f}$. 
„Heiden` gleichermaßen Toleranz ${ }^{71}$ erfuhren. Immerhin ließ dies auf die breiteste Akzeptanzbasis ${ }^{72}$ hoffen.

Während der zivile Sektor ausschließlich mit ausgewiesenen Verwaltungsexperten der stadtrömischen Senatsaristokratie besetzt wurde, fielen die hohen Positionen des militärischen Kommandos an Goten und Römer gleichermaßen. In der Stellung des magister utriusque militiae ${ }^{73}$ erreichte Alarich sein vorrangiges Ziel: die Integration in römische Strukturen ${ }^{74}$. Damit war Alarich, wie sich Demandt treffend ausdrückte, „durch einen Federstrich vom Reichsfeind in einen Reichsgeneral verwandelt"“75. Athaulf, der Schwager des Alarich, erhielt die Stellung des comes domesticorum equitum. ${ }^{76}$ Ihm wurde ein hoher römischer Offizier zur Seite gestellt. Valens ${ }^{77}$, der Befehlshaber der dalmatischen Truppen, der noch im Dienst des Honorius erfolglos gegen Alarich gefochten hatte, war neben Jovius der zweite Überläufer, der sich nun in hoher Position unter Attalus wiederfand. So wurde diesem das zweite Heermeisteramt angetragen $^{78}$ und damit der absoluten Vormachtstellung der foederati im militärischen Sektor ein Riegel vorgeschoben. Zosimos hielt hierzu fest, dass „die Römer indes gar sehr frohlockten, da sie Obrigkeiten erhalten hatten, die alles wohl einzurichten wussten. [...]“79. Eben dieser wohlgeordnete Zustand des Gemeinwesens, der maßgeblich von Angehörigen der Senatsaristokratie Roms getragen wurde, verschaffte der Regierung des Priscus Attalus einen nicht zu unterschätzenden Vorteil gegenüber der Administration des Honorius, die, tief verstrickt in innere Machtkämpfe, ${ }^{80}$ kaum

71 Soz. 9,9,1, hier gerade auch auf die Arianer bezogen; so auch GOLTZ (2002a) 563; allgemein auch CECCONI (2013) 161 und MELLÁ (1984/1983) 55.

72 Insofern ist SZIDAT (2010) 261, wonach Attalus weitgehend isoliert gestanden haben soll, keineswegs vorbehaltlos zu folgen, denn letztlich vertrat das Regime des Attalus gerade auch durch seine hohen Amtsträger sowohl ,Heiden', als auch orthodoxe und arianische Christen gleichermaßen.

73 Soz. 9,8,1 und Zos. 6,7,2.

74 Vgl. KAMPERS (2008) 100; BURNS (1994) 164-168; WOLFRAM (1990) 147 und MATTHEWS (1975) $289 \mathrm{f}$. So konnte z. B. Alarich seine Truppen nun durch die annona militaris versorgen lassen; CTh.1,22,4. Vgl. hierzu ausführlich zuletzt MITTHOF (2001) unter Angabe älterer Literatur; zusammenfassend vgl. KOLB (2000) 68f.; DRECOLL (1997) 124-126, und OTT (1995) 143-145.

75 DEMANDT ${ }^{2}(2007) 173$.

76 Soz. 9,8,1. Zur Stellung des Athaulf vgl. LOTTER (2003) 94-80 und WOLFRAM (1990) 171-173. 77 Valens 2 (PLRE 2, 1137).

78 Zos. 5,45,1f. u. 6,7,2. Vgl. hierzu FITZ (1983) 80 f.

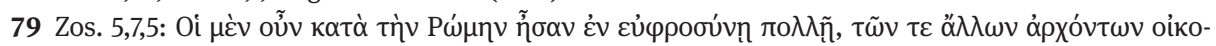

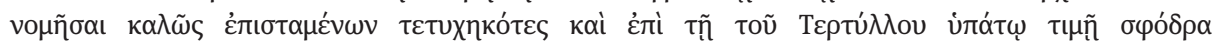

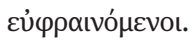

80 Vgl. SZIDAT (2010) 314 und LÜTKENHAUS (1998) 24-31. Nach dem Abgang des Jovius, der bis dato vermutlich im Verbund mit Allobich (PLRE 2, 61; magister equitum domesticorum) den Kaiser und seinen Hof dominierte (LÜTKENHAUS (1998) 25f.), wird ein Machtkampf am ravennatischen Hof entfesselt: Erst wird Eusebius 9 (PLRE 2, 429; PSC), der die führende Stellung am Hof für sich selbst beanspruchen wollte (gewiss aufgrund seiner persönlichen Nähe zum Kaiser), von Allobich ermordet und dann büßt auch Letzterer Ende 409 sein Leben ein (Olymp. fr. 15,1 (Blockley) und Soz. 9,12,5), woraufhin möglicherweise wiederum Olympius seinen Einfluss zurückgewinnen konnte. Diese inneren Machtkämpfe hatten zur Folge, dass der Hof keine stringente politische Linie verfolgen konnte und weit- 
noch handlungsfähig war. Die Ausgangslage für Attalus und Alarich war demnach keinesfalls so aussichtslos wie dies immer wieder unterstellt wurde. Dies zeigte sich nicht nur darin, dass Honorius Vorkehrungen für die eigene Flucht treffen ließ und sogar erwogen wurde, Attalus als Mitkaiser ${ }^{81}$ anzuerkennen. Auch Konstantinopel schien der Ernsthaftigkeit der Lage Rechnung zu tragen, indem die Häfen und Grenzen des Ostens ${ }^{82}$ gesperrt und überwacht wurden.

Für die Herrschaft des Attalus fiel die Entscheidung jedoch in Africa. So wurde bereits rasch nach der Erhebung des Attalus ein gewisser Constans ${ }^{83}$ als comes Africae nach Karthago entsandt, der sich aber gegenüber Heraclianus ${ }^{84}$, dem von Ravenna eingesetzten Amtsinhaber, nicht behaupten konnte. In einem zweiten Anlauf sollten Gesandte die Treue Nordafrikas mit hohen Geldzahlungen ${ }^{85}$ erkaufen. Doch auch dies scheiterte. In der Folge war eine Versorgungskrise in Rom $^{86}$ nicht mehr zu verhindern. Dennoch soll es Attalus vehement abgelehnt haben, auch nur eine geringe Zahl an gotischen Truppen nach Africa übersetzen zu lassen. ${ }^{87}$ Schon die antiken Geschichtsschreiber wollten hierin nichts als einen Beweis der schieren Torheit des Attalus erkennen. ${ }^{88}$ Lütkenhaus hingegen hat völlig richtig erkannt, dass Attalus die Goten nur solange in Abhängigkeit halten konnte, wie diese sich keiner eigenen Versorgungsgrundlage bemächtigen konnten. ${ }^{89}$ Die Hoffnung, Africa kampflos zu gewinnen und unter die Kontrolle des Senats zu stellen, war dabei keineswegs eine

gehend handlungsunfähig blieb, was sich letztlich auch darin zeigt, dass es Alarich nicht möglich war, im ravennatischen Hof einen verlässlichen Verhandlungspartner zu finden. Vgl. SZIDAT (2010) 343. 81 Zos. 6,8,1-3; Olymp. fr. 10,1 u. 14 (Blockley); Soz. 9,8,5. Vgl. hierzu SZIDAT (2010) 316 und PASCHOUD 1989, $48 \mathrm{f}$.

82 CTh. 7,16,2 (24.4.410). Vgl. LÜTKENHAUS (1998) 32 u. Anm. 57.

83 Constans 2 (PLRE 2, 310); Zos. 6,7,8; 6,9,1 und Soz. 9,8,3.

84 Heraclianus 3 (PLRE 2, 539f.).

85 Zos. 6,9,2. Zur Aufteilung in zwei Versuche vgl. LÜTKENHAUS (1998) 35, Anm. 64. Denkbar ist auch, dass mit diesen Geldern der von Constans organisierte Widerstand gegen Heraclianus, der mit der Ermordung des Constans einen Rückschlag erfuhr, weiter finanziert werden sollte.

86 Zos. 6,11,1.

87 Zos. 6,12,1; Soz. 9,8,8 und Olymp. fr. 10 (Blockley). An Alarichs Interesse, seine eigenen Truppen nach Africa schicken zu lassen, um die eigene Versorgung sicherstellen zu können, besteht kein Zweifel, immerhin unternahm er einen eigenen Versuch sich nach der Plünderung Roms 410, Nordafrikas oder vielleicht auch nur Siziliens zu bemächtigen (Olymp. fr. 16 (Blockley) oder Iord. Get. 157). Zweifelhaft scheint m.E. jedoch die geschlossene Haltung des Senats, wie sie Zosimos (Zos. 6,12,1) schildert.

88 Zos. 6,9,3.

89 LÜTKENHAUS (1998) 35. Insofern ist ernsthaft zu hinterfragen, ob es für den Einsatz ,barbarischer، Truppen tatsächlich eine breite Mehrheit im Senat gab (Zos. 6,12,1). Immerhin entsprach dies nicht gerade den ökonomischen Interessen jener Senatoren, die über reiche Besitzungen in Africa verfügten, die bislang, im Gegensatz zu ihren italischen Gütern, vom Krieg noch unversehrt waren. Hiervon geht jedoch LÜTKENHAUS (1998) 36, aus, obgleich nach Soz. 9,8,8, und Olymp. fr. 10 (Blockley) sich der Senat dagegen entscheidet. 
realitätsferne Utopie. ${ }^{90}$ Zum einen standen beträchtliche Teile der Bevölkerung, Gemeinden und Ländereien Nordafrikas unter dem senatorischen Patronat. ${ }^{91}$ Zum anderen hatten einzelne Anhänger des Attalus, wie Marcianus und Jovius, vormals hohe Positionen in der Verwaltung der afrikanischen Provinzen bekleidet und besaßen daher Kontakte zu dessen Verwaltungsstab. ${ }^{92}$ Daneben bestand auch die Aussicht mittels einer liberaleren Religionspolitik die Unterstützung der Donatisten ${ }^{93} \mathrm{zu}$ gewinnen.

Das Scheitern in Africa bedeutete das Ende der Herrschaft des Attalus. Außerstande seinen Willen durchzusetzen, entließ Alarich seinen Kaiser, ${ }^{94}$ der am Ende widerspenstiger war, als es von ihm erwartet wurde. Weit weniger trug die Spannung zwischen zwei ungleichen Partnern, der stadtrömischen Senatsaristokratie auf der einen und Alarichs Militärgefolge auf der anderen Seite, zum Scheitern des Bündnisses bei. ${ }^{95}$ Wesentlich unüberbrückbarer waren dagegen die zwei gegensätzlichen Konzepte der kaiserlichen Herrschaft und die daran geknüpften Erwartungen, die sich

90 Vgl. LÜTKENHAUS (1998) 37. Dies wird auch durch die Darstellung des Zosimos (Zos. 6,8,3) deutlich, wonach Heraclianus nicht von vorneherein die Oberhand gewann und um seine Position tatsächlich rang. Hiervon machte nicht zuletzt auch Honorius sein Verbleiben im Westen abhängig (Zos. 6,8,4).

91 Vgl. KRAUSE (1987) 294f. Ein gutes Beispiel liefert die Vita der Hl. Melania (bes. Vit. Mel. Lat. XXI), die die umfangreichen nordafrikanischen Besitzungen anführt und Güter erwähnt, welche in ihrer Größenordnung die Stadt Thagaste in den Schatten stellten; ferner auch die Patronatstäfelchen aus der domus der Valerier (CIL 6, 1684-1689; u. a. praeses Byzacenae) oder die Besitzungen der Anicii, Aradii, Caeionii und anderer Angehöriger der stadtrömischen Senatsaristokratie in Nordafrika. Vgl. OVERBECK (1973) bes. 41 f. Die Anicii und Aradii sahen den Ursprung ihrer Häuser überdies in Africa (Amm. 27,11,1). Vgl. PANCIERA (1986) 547-572.

92 Auffällig ist, dass ein Großteil der Gouverneure von Numidia und Byzacena aus dem Haus der Caeionii, Valerii oder Aradii stammten, die Anicii überwiegend als Prokonsuln der Africa Proconsularis amtierten. Vgl. WICKHAM (2005) 163; LANCON (2001) 64 f. und bes. OVERBECK (1973) 23 u. 29. Eine Aufarbeitung des prosopographischen Materials für das 4. bis 6. Jh. bietet OVERBECK (1973) 23-40. Diese stadtrömischen Häuser hatten somit besonders starke Beziehungen zu den nordafrikanischen Provinzen. Die mangelnde Bereitschaft der Anicier, das Regime des Attalus zu unterstützen, konnte sich hierbei überaus hinderlich im Hinblick auf die erstrebte Kontrolle über die wichtigste Provinz, Africa Proconsularis, auswirken.

93 Vor 409 wurden die Gesetze gegen Donatisten und ,Häretiker durch den ravennatischen Hof zusätzlich verschärft (u. a CTh. 16,5,38 a. 12.2.405; CTh. 16,5,39 a. 8.12.405; Const. Sirm. 12 a. 25.11.407; CTh. 9,40,19 a. 11.11.408), so dass eine tolerantere Religionspolitik von Seiten der Administration des Attalus gewiss Anklang bei den zahlreichen nordafrikanischen Donatisten gefunden hätte. Vgl. hierzu auch OVERBECK (1973) 50-52.

94 Zos. 6,12,2 und Philost. 12,3. Nur Soz. 9,8,10 lässt den Attalus das Diadem selbst niederlegen, was zumindest insofern denkbar wäre, wenn Attalus die Konsequenzen aus dem Scheitern seiner Politik in Africa selbstständig tragen wollte, um damit dem Handeln Alarichs oder sogar einem gewaltsamen Ende zuvorzukommen.

95 Die Hinrichtung des Valens 2 Anfang 410 (Zos. 6,10,1), deren genaue Umstände nicht mehr zu rekonstruieren sind, deutet zumindest auf innere Spannungen hin; ob sich diese zwischen den Truppen des Alarich und römischen Verbänden abspielten oder aber eine Tendenz aufkam, sich wieder der Herrschaft des Honorius zu unterstellen, muss jedoch offenbleiben. 
unvereinbar gegenüberstanden. Auf der einen Seite befand sich ein vom Senat erhobener Kaiser, der ganz im Selbstverständnis früherer principes Herrschaft und aktive, selbstbestimmte Regierungstätigkeit auf sich vereinen wollte. Auf der anderen Seite formierten sich die machtpolitisch relevanten Drahtzieher, wie der magister militum Alarich, aber auch der patricius Jovius, ${ }^{96}$ die einen fügsamen und lenkbaren Kaiser erwartet hatten. Noch verheerender wirkte sich allerdings aus, dass der Senat nicht mehr über die auctoritas verfügte, die Treue der Provinzen gegenüber dem caput mundi einzufordern. ${ }^{97}$ Das politische Gewicht des Senats reichte offensichtlich nicht aus, um die Provinzen und die dort eingesetzten zivilen und militärischen Amtsträger zum Abfall von Ravenna und Konstantinopel zu bewegen. Damit waren auch für Alarich der Senat und Attalus politisch kaum noch von Nutzen. ${ }^{98}$

Trotz des Scheiterns des Attalus bleibt dieses Intermezzo des Senats im Ringen um kaiserliche Herrschaft überaus aufschlussreich, denn offenkundig waren sich beträchtliche Teile der Senatsaristokratie der gegenwärtigen strukturellen Schwäche des Kaisertums nur allzu bewusst und wollten dem entgegenwirken. Ein würdig-fortgeschrittenes Alter, welches von Lebenserfahrung und einer gefestigten Persönlichkeit zeugte, war jedoch genauso wie eine tadellose Abstammung und Amtsführung, die ganz den senatorischen Werten und römischen Traditionen verpflichtet war, weitgehend unerheblich für die Eignung als Kaiser geworden. Ein Herrscherbild wie es zumindest in der Überlieferung durch Tacitus (275/276) verkörpert wird, den noch die Historia Augusta und Aurelius Victor als „Senatskaiser“ ausufernd mit Lob bedacht hatten, ${ }^{99}$ erwies sich als nicht praktikabel.

96 So soll dieser sich nach Zos. 6,9,1-5 dem Willen des Attalus verweigert haben und überdies daran gegangen sein, gegen ihn zu intrigieren, indem er Attalus vor Alarich in Misskredit gebracht haben soll (auch Zos. 6,12,3).

97 Hier ist an den im Jahr 238 ergangenen Apell des Senats, der die Provinzen - allerdings erfolgreich

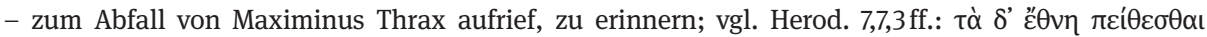

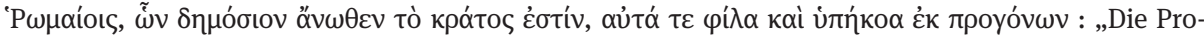
vinzen sollten den Römern gehorchen, denen von alters her die Befehlsgewalt zu eigen sei und denen sie selbst befreundet und untertan wären seit der Zeit ihrer Vorfahren." (Übersetzung nach MÜLLER (1996)). Vgl. SHA. Max. et Balb. 15,3. Dass Konstantinopel mit dem Misserfolg senatorischer Gesandtschaften nicht von vornherein gerechnet hatte, scheint CTh. 7,16,2 (24.4.410) zu belegen.

98 Zum weiteren Schicksal des Attalus, nach seiner Auslieferung 416 verbannt auf die Insel Lipara, vgl. Philost. 12,4f.; Olymp. fr. 14 u. fr. 26,2 (Blockley); Prosp. Tiro 1257 (s. a. 417) (Chron. min. I. 468) und Paul. Pell. euch. 292-303. Mal. 13,48, behauptet dagegen wohl fälschlich, dass Attalus hingerichtet wurde. Zur Bestrafung des Usurpators, zwei abgeschlagene Finger, vgl. SZIDAT (2010) 325 mit Anm. 1350; ferner DOYLE (2019) 180f. und MCCORMICK 2(1990) $57 \mathrm{f}$.

99 SHA. Tac. 4,3-4: Aufgrund seiner Stellung, seines Vorlebens, seiner Gesinnung, Ernsthaftigkeit, Bildung und Erfahrung der Kaiserherrschaft würdig; den Vorzug des Greisenalters, welches Weisheit versprach, betont SHA. Tac. 5,2, in der Akklamation des Senats dreißigmal: „Wir wählen deinen Geist, nicht deinen Leib!“ und SHA. Tac. 6,2: „Wir haben einen betagteren Mann zum Kaiser gemacht, einen Mann der für alle wie ein Vater sorgen soll.“ Zum unglücklichen Umstand, einen jungen Kaiser zu haben, SHA. Tac. 6,4f. Aur. Vict. 36. Eine Ausnahme stellt Zonaras (Zon. 12,28) dar, der angibt, dass 
Hoch war der Preis, den der Senat, die stadtrömische Senatsaristokratie und die Stadt Rom im August 410 zu zahlen hatten. Die Amnestie, die schon am 12. Juni 411 von Honorius erlassen wurde, ${ }^{100}$ zeigte, dass selbst der Kaiser gewillt war, sich angesichts des Elends, welches über Rom und seine Senatoren hereingebrochen war, versöhnlich zu zeigen. Eine gewisse Schadensbegrenzung in eigener Sache gelang der gens Anicia, die sich von Beginn an gegenüber der Usurpation des Attalus ablehnend verhielt. ${ }^{101}$ Ihre Treue gegenüber der theodosianischen Dynastie sollte sich bezahlt machen, so dass nach 418 die Stadtpräfektur stark von den Aniciern dominiert wurde. ${ }^{102}$ Entsprechendes gilt wohl auch für Angehörige aus den Häusern der Decii und CaeioniiRufii. ${ }^{103}$ Dies wirft dann auch nochmal ein bezeichnendes Licht auf die innere Beschaffenheit des Senats.

Obwohl der Senat einstimmig die Wahl des Attalus gebilligt haben soll, ${ }^{104}$ ist es offensichtlich, dass sich nicht mehr die Gesamtheit der stadtrömischen Senatsaristokratie von diesem Gremium vertreten ließ. Dies zeigt, dass es eine vom Senat bestimmte Politik auch unter Attalus nicht gab. So waren auch nicht der gesamte Senat oder die gesamte stadtrömische Senatsaristokratie nach 410 diskreditiert, sondern nur die Freunde und Anhänger des Attalus. Auffallen muss überdies der Umstand, dass mit dem aus Gallien stammenden Rutilius Claudius Namatianus ${ }^{105}$ und dem stadtrömischen Aristokraten Rufius Antonius Agrypnius Volusianus ${ }^{106}$ noch einmal zwei namhafte ,Heiden` die Stadtpräfektur 414 und 416 übernehmen konnten. Folglich gelang es Attalus auch nicht, das Heidentum hinter sich als Kaiser zu vereinen. In

Tacitus vom Heer gewählt wurde und dann erst der Senat um Bestätigung gebeten wurde. Zu den SHA.Stellen vgl. BALDINI (2004) 84-104. Zu Tacitus vgl. auch JOHNE (2008) 379-393.

100 Soz. 9,8,10; CTh. 9,38,11 (12.2.410?). Die Datierung wird von DELMAIRE auf den 12.6.411 korrigiert; vgl. DELMAIRE (1997) 111-126, hier 125, und ders. (1987) 829-840, hier 838f.; SZIDAT (2010) 336 Anm. 1426, folgt ihm hierin.

101 Zos. 6,7,4. Vgl. auch MATTHEWS (1975) 297-300.

102 Dass die Anicier nicht gleich nach 410 in hohe Ämter eingesetzt wurden, könnte mit den Ereignissen um die Domus Pinciana und der Handlungsweise der Anicia Faltonia Proba (Prok. BV. 1,2,27) zusammenhängen; vgl. hierzu Kap. 8.4. So finden sich in diesem Amt Aurelius Anicius Symmachus 6 (PLRE 2, 1043f.); zur Verwandtschaft mit den Aniciern vgl. CAMERON (2012) 153-156; Petronius Maximus 22 (PLRE 2, 749; vgl. Kap. 4.3) und Faustus 8 (PLRE 2, 452-454); vgl. CAMERON (2012) 148-150. 103 Albinus 7 (PLRE 2, 50 f.; PVR 414). Eine Identifizierung mit Fl. Albinus 10 (PLRE 2, 53; PVR 426, Cos. 444 etc.) ist nicht unwahrscheinlich; würde aber bedeuten, dass der PVR von 414 in sehr jungen Jahren das Amt bekleidet haben müsste (vgl. Rut. Nam. 1,470: vitae flore puer). Vgl. STICKLER (2002) 281 und WEBER (1989) 472-497. Rufius Antonius Agrypnius Volusianus 8 (PLRE 2, 1184f.; PVR 416). Ferner auch der stadtrömische Aristokrat Palladius 19 (PLRE 2, 822ff.; Cos. 416 und PPO bis 421; CIL 6, 41383 (AE 1928,80) aus einer domus auf dem Aventin).

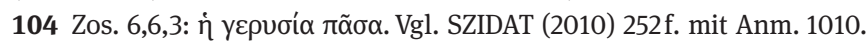

$105 \mathrm{Zu}$ dessen Religionszugehörigkeit, worüber gemäß De reditu suo kein Zweifel besteht, vgl. VON HAEHLING (1978) 406f.

$106 \mathrm{Zu}$ dessen Religionszugehörigkeit, worüber auch nach Vit. Mel. 50-55 kein Zweifel bestehen kann, vgl. VON HAEHLING (1978) 319f. Neben der Position des PVR hatte Rutilius Claudius Namatianus 412 auch die des magister officiorum inne. 
Anbetracht dessen ist es überaus zweifelhaft, ob ein heidnisches oder ein dem Heidentum nahestehendes Kaisertum überhaupt angedacht war.

\subsection{Johannes Primicerius und der Bruch mit der theodosianischen Dynastie}

Zu den „Senatskaisern“ zählt Demandt neben den Usurpatoren Eugenius, Priscus Attalus und Petronius Maximus auch den primicerius notariorum Johannes. ${ }^{107}$ Nach dem Ableben des Honorius am 15. August 423 entstand im Westen ein Machtvakuum. ${ }^{108}$ Aus dem Selbstverständnis des ungeteilten Imperiums fiel die Alleinherrschaft formal an Theodosius II. ${ }^{109}$ Dennoch, ohne einen Kaiser, der im Westen präsent war und dem Hof und seinen Amtsträgern letztlich eine Existenzberechtigung gab, ging es nicht. Nach vier Monaten Wartezeit kam es so am 20. November 423 zur Usurpation. ${ }^{110}$ Unerwartet ist hingegen das Ergebnis, denn keineswegs ein prominenter Vertreter der stadtrömischen Aristokratie oder des militärischen Kommandos war zur Usurpation bereit, sondern der primicerius notariorum Johannes, ${ }^{111}$ der im Gegensatz zu den höheren Ämtern der Hof- und Reichsverwaltung nur den viri spectabilis ${ }^{112}$ angehörte.

107 U. a. DEMANDT (2013a) 69 [1980]; nachfolgend ders. ²(2007) 331; auch MAZZARINO (1980) 804 f. und DEICHMANN (1974) 93; zurückhaltender bezüglich der Begrifflichkeit HENNING (1999) 272; kritisch bezüglich der Terminologie SZIDAT (2010) 264 mit Anm. 1058.

108 Placidus Valentinianus war zwar bereits kurz nach seiner Geburt zum nobilissimus puer (jedoch nicht zum Caesar) und damit zum präsumtiven Nachfolger des kinderlosen Honorius bestimmt worden; zum Titel vgl. INSTINSKY (1952b). Dieser wurde jedoch aufgrund von hart geführten politischen Auseinandersetzungen am ravennatischen Hof von seiner Mutter nach Konstantinopel verbracht. Vgl. BÖRM (2013) 64-67.

109 So Hyd. Lem. 72 (Chron. min. II. 82) und Beda Ven. Hist. eccl. Brit. 1,13. Vgl. BÖRM (2014) 209f. u. ders. (2013) 65. Im eigentlichen Sinne war somit kein Interregnum eingetreten. Im eigentlichen Sinne war somit kein Interregnum eingetreten. PFEILSCHIFTER (2013) 484, spricht von einem Interregnum; ebenso BRANDT ${ }^{2}(2005) 79$.

110 Olymp. fr. 39 (Blockley). Zum genauen Datum vgl. Ann. Rav. s. a. 423 und Fast. Merseb. s. a. 423; unter Bezugnahme auf die Chronisten diskutiert bei SEECK (1921) 408.

111 PLRE 2, 594f. (Joannes 6); ferner VON HAEHLING (1988) 97-102, hier 96 f. Über Herkunft, Abstammung und Werdegang des Johannes lässt sich den Quellen nichts entnehmen. Die Angabe, dass dieser Gote (Nic. Call. 14,7) oder Vandale (Theoph. a. m. 5938) gewesen sei, gründet vermutlich auf einer Verwechslung mit Johannes 13 (PLRE 2, 597). Über seine Position als primicerius notariorum besteht nach Socr. 7,23,3 (= Ioh. Ant. fr. 195), Chron Gall. 452 (s. a. 423), Nic. Call. 14,7 und Theoph. a. m. 5915 kein Zweifel. Aus der Notitia Dignitatum geht hervor, dass der primicerius notariorum und sein Büro verantwortlich für die Ausstellung der kaiserlichen Diplome waren, durch welche die Ernennung hoher ziviler und militärischer Ämter erfolgte (Not. Dig. occ. 16,4f.). Vgl. hierzu SCHARF (2005) $4 \mathrm{f}$. 112 Generell unterstand der primicerius notariorum direkt dem Kaiser und nicht dem magister officiorum (Not. Dig. oc. 16,4) und war ebenso wie der primicerius sacri cubiculi (Not. Dig. occ. 14,1; zu Unterschieden vom praepositus), der castrensis (Not. Dig. occ. 15,1;3;7) und die magistri scriniorum (CTh. 6,11) im Rang der vir spectabilis; vgl. hierzu BEYELER (2011) 229f.; DEMANDT 2(2007) 278f. u. 288f.; DELMAIRE (1995) 49f. Zur Bedeutung der notarii vgl. VOGLER (1979) 192-197. 
Stützen konnte sich Johannes in erster Instanz auf die bedeutende Personengruppe der notarii, der er selbst vorstand. ${ }^{113}$ Die Stellung eines tribunus et notarius stellte eine attraktive Einstiegsposition für die Söhne der bedeutenden Häuser Roms dar. ${ }^{114}$ Damit hatte ihr Amtsvorsteher wohl auch gute Kontakte zur stadtrömischen Senatsaristokratie.

In seiner Funktion, die Ernennungskodizille des laterculum maius zu verwalten, war der primicerius notariorum bestens vertraut mit den Ämtern und ihren Amtsträgern, was Johannes sowohl für die zivile Administration als auch für den militärischen Sektor zu einem akzeptablen Prätendenten für die Kaiserherrschaft im Westen werden ließ. Wie schon im Fall des Priscus Attalus ${ }^{115}$ fiel die Wahl auf einen Mann, der sich durch seine Amtsführung als fähiger und verständiger Verwaltungsexperte empfahl und damit abermals erhoffen ließ, dass unter ihm das Gemeinwesen wohlgeordnet sein würde. Über 100 Jahre später wird Prokop diesen Usurpator noch in höchsten Tönen loben:

Dieser, ein Mann von milder und einsichtiger Art, verstand die Kunst, sich Verdienste zu erwerben. In den fünf Jahren [tatsächlich knapp anderthalb Jahre] seiner eigenmächtigen Herrschaft regierte er mit Mäßigung, schenkte keinem Denunzianten Gehör, ließ wissentlich keine Unschuldigen hinrichten, noch sich zur Aneignung des Privatvermögens verleiten, [...]. ${ }^{116}$

Obwohl der primicerius notariorum Johannes dem ravennatischen Hof zuzuordnen war, ${ }^{117}$ erfolgte seine Investitur nicht in Ravenna, sondern in Rom ${ }^{118}$ im Kreis der

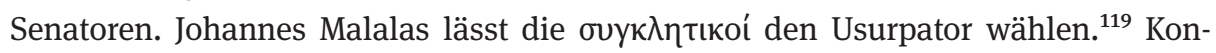
kreter benennen die Annales Ravennatenses den Senat, ${ }^{120}$ der aus Furcht vor einer

113 Nov. Val. 6,3 (444) nennt 30 notarii; Lib. or. 2,44ff. u. 18,134 beklagt den wachsenden Einfluss der notarii. Vgl. BEYELE (2011) 229f.; DEMANDT 22(2007) 288; ausführlicher TEITLER (1985); KUHOFF (1983) 195-221; ferner CLASSEN (1983) 67-71 und VOGLER (1979) 192-197.

114 So hatte diese Stellung Eucherius (396-408), der Sohn des Stilicho, inne; ebenso Fl. Iunius Quartus Palladius (vor 408/409), Petronius Maximus (415) und Fl. Peregrinus Saturninus (?); ferner auch Claudianus (397 und 404).

115 Vgl. Kap. 4.1.

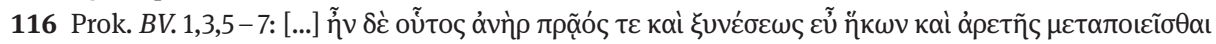

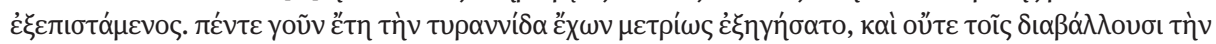

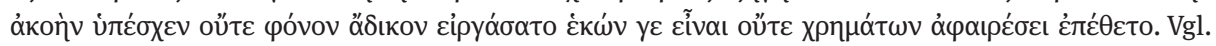
Philost. 12,13, wo die Regierungszeit richtig mit anderthalb Jahren angegeben wird. Die erstaunlich positive Wertung wird so auch von Theoph. a. m. 5915 und Marcell. Com. s. a. 425 geteilt.

117 SZIDAT (2010) 277 u. 344 betont zu Recht, dass seine Herrschaft ihren Ausgang am kaiserlichen Hof, im Kreis des comitatus, nimmt.

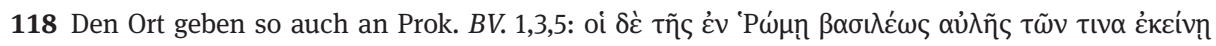

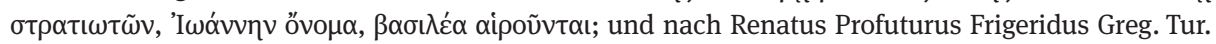
Franc. 2,8: apud urbem Romam tyrannum Iohannem in imperium surrexisse.

119 Mal. 13,50; zur Begrifflichkeit in seiner Anwendung auf den Senat oder auch auf eine Gruppe von Senatoren oder anderen Amtsträgern am Hof bzw. aus dem Militär vgl. SZIDAT (2010) 386f.; zur Erhebung vgl. MATTHEWS (1975) 379f.

120 Ann. Rav. s. a. 423. 
Verknappung der Getreideversorgung, bedingt durch die feindliche Haltung des Bonifatius in Africa, ${ }^{121}$ sich den Johannes zum Kaiser wählte. In Anbetracht des nur knappen und unvollständigen Bilds, welches die Quellen von der Usurpation des Johannes geben, ${ }^{122}$ sind Zweifel natürlich immer angebracht. Gewiss spricht aber einiges dafür, dass der Senat zur Investitur des Johannes bemüht wurde. Es muss auch dem Hof und dem engeren Kreis der Unterstützer des Johannes ${ }^{123}$ durchaus bewusst gewesen sein, wie fragil die Legitimationsgrundlage war, die sie bieten konnten. Sowohl für die Anerkennung im Westen als auch die erhoffte Duldung Konstantinopels war die Akklamation durch eine verschworene Clique am Kaiserhof oder eine vereinzelte Heeresgruppe zu vermeiden. Ferner bedurfte es der Unterstützung der einflussreichen und finanziell potenten Häuser Roms.

Der Münzprägung ist deutlich zu entnehmen, dass Konstantinopel von Anfang an in die Pläne miteinbezogen wurde und die Herrschaft zweier Augusti, des D(ominus) N(oster) THEODOSI-VS P(ius) F(elix) AVG(ustus) ${ }^{124}$ und des D. N. IOHAN-NES P. F. AVG. ${ }^{125}$, von westlicher Seite angestrebt war. Folglich fand auch die Sieghaftigkeit des Herrscherkollegs, VICTORI-A AVGVSTORVM ${ }^{126}$, auf den Solidi ihren Platz. Obgleich unter den Siliquae auch die Legende VRBS - ROMA mit der stehenden Roma auftritt, bleibt die Urbs aeterna in der Münzprägung eher unterrepräsentiert. Dafür, dass Johannes sein Herrschaftszentrum in Oberitalien, vor allem in Ravenna und Mailand, einrichtete, sprechen auch die Goldprägungen, die ausschließlich in den dortigen Münzstätten vorgenommen wurden, wohingegen in Rom lediglich Bronze ${ }^{127}$ geprägt

121 PLRE 2, 237-240; im Zusammenhang mit der Erhebung des Johannes verwies bereits SEECK (1920) 89f. auf die zentrale Bedeutung des Bonifatius in Africa; nachfolgend u. a. auch SEIBEL (2006) 114; STICKLER (2002) 29; DE LEPPER (1941) 40 - 46; STEIN (1928) 282-285. DE LEPPER (1941) 44 sah in Bonifatius gar den maßgeblichen Akteur, der aufgrund der Rivalität zu Castinus (PLRE 2, $269 \mathrm{f}$. (Fl. Castinus 2)) die Reichseinigung unter Theodosius II. hintertrieb.

122 Basierend auf den literarischen Quellen fällt die Darstellung der Usurpation des Johannes bei SEIBEL (2006) 113-116 sehr knapp aus; auch SZIDAT (2010) liefert keine annähernd ausreichende Darstellung. Eine aktuelle, ausführlichere Behandlung ist daher durchaus geboten.

123 Hierbei handelt es sich zunächst vermutlich um das Büro des primicerius notariorum selbst; des Weiteren hochrangige Angehörige des comitatus, vermutlich auch mit Sitz im consistorium; vgl. SZIDAT (2010) 344. Ferner war auch die Unterstützung der protectores domestici unter dem comes domesticorum unentbehrlich.

124 RIC 10, 1909, 1914, 1915, 1918, 1919, 1922 (T3 und T5).

125 In der Variation RIC 10, J1: D. N. IOHAN-NES P. F. AVG. und J2: D. N. IOHANN-ES P. F. AVG. 126 RIC 10, 1901-1906, 1908-1911; auf dem Revers ist entweder der Kaiser nach links stehend mit Standarte in der rechten und von Victoria bekrönten Globus in der Linken einen ,Barbaren“ niedertretend dargestellt oder Victoria nach rechts stehend bzw. nach links sitzend mit Siegeskranz in der rechten Hand und zum Teil Kreuz bekrönten Globus in der linken. Eine Ausnahme stellt RIC 10, 1903 dar, wo Victoria nach rechts sitzend ein Schild mit dem Christogramm beschriftet und ein von rechts kommender Erote (bzw. geflügelten Genius) abgebildet ist. Des Weiteren zeigen auch die mit der Legende SALVS REI - PVBLICE versehenen Bronzemünzen Victoria (RIC 10, 1912-1923).

127 Unter Honorius und Valentinian III., die häufig, gerade in der späteren Phase ihrer Herrschaft, in Rom residierten werden in der stadtrömischen Münze auch Solidi geprägt (Honorius: RIC 10, 1250 - 
wurde. Eine Besonderheit stellt vor allem das Bildnis dar. Johannes wird mit Bart dargestellt. Das hierdurch zum Ausdruck gebrachte Herrscherprofil versprach einen tatkräftigen und erfahrenen Kaiser, ${ }^{128}$ der stolz das Zeichen seines reifen Alters präsentierte. Damit konnte sich Johannes vor allem vor den hohen Militärs, den Soldaten, der Reichsadministration und nicht zuletzt vor all jenen empfehlen, denen es nach einer Alternative zum princeps puer bzw. clausus ${ }^{129}$ verlangte. Gleichsam positionierte sich der Usurpator mit der Betonung auf das eigene würdige Alter als Alternative zu dem erst zweiundzwanzigjährigen Theodosius und seinem vierjährigen Neffen Placidus Valentinianus. Die stadtrömische Senatsaristokratie mochte darüber hinaus in Johannes einen Mann der paganen Bildung ${ }^{130}$ erkennen, der wie einst Kaiser Juli$a^{131}$ oder der Usurpator Eugenius ${ }^{132}$ den Bart stehen ließ.

Wenngleich von der Gesetzgebung des Johannes sich nichts erhielt, verweisen doch zumindest die rasch nach seinem Sturz erlassenen Gegengesetze, die sich noch im Codex Theodosianus und den Constitutiones Sirmondianae finden lassen, auf einen beachtlichen Kurswechsel, den die Administration des Usurpators insbesondere in der Religionspolitik eingeschlagen hatte. Offenbar sorgte der tyrannus dafür, dass allen ,Sektierern' und wohl auch ,Heiden‘ mit Milde ${ }^{133}$ begegnet wurde. Im Gegenzug

1259, 1352; Valentinian III.: RIC 10, 2014 - 2017, 2034, 2038-2046). Prägungen des Johannes mit Stempel der Münzstätte Rom (R. M.): RIC 10, 1912-1923 (SALVS REI - PVBLICE).

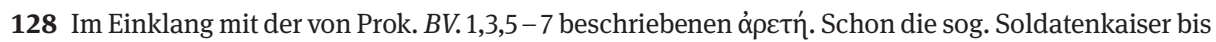
zu den Tetrarchen bevorzugten ein Herrscherbild, welches den Kaiser mit dem kurzen „Soldatenbart“ zeigte. Vgl. DEMANDT ${ }^{3}(2007) 113 \mathrm{f}$.

129 Treffend hierzu die Herrscherkritik des Synesius, der Kaiser beschwor, „die genügsam und anspruchslos waren“ und „sich von der Sonne bräunen ließen“, während sie die Truppen selbst führten und nicht „wie die Pfauen“ waren oder „Salamander, die sich nicht gerne ans Sonnenlicht wagen“ (Synes. Reg. 11). Vgl. KOLB (2001) 19f.; SCHLINKERT (1998a) 133f. und STRAUB (ND 1964) $205 \mathrm{f}$.

130 Die stehengelassene Barttracht wurde so auch von den Philosophen und Personen, die der paganen Bildung besonders nahestanden, getragen. Im engeren Sinne ist aber hier aufgrund der kurzen Länge des Bartes nicht von einem „Philosophenbart“ im klassischen Sinne auszugehen; vgl. DEMANDT 32(2007) 113f.; DANGUILLIER (2001) 14-19; DANGUILLIER (2001) 19 Anm. 187 klassifiziert den Bart des Johannes als einen „lockigen Kurzbart“, der zwischen „Soldaten-“ und „Philosophenbart“ zu verorten ist und so z.T. später auch von Theodosius II. (RIC 10, Taf. 7) und Leo I. (RIC 10, Taf. 23) getragen wurde.

131 Julian, der sich zur heidnischen Kultur und Religion bekannte, war stolz auf seinen „Philosophenbart“ und war u.a. deswegen auch dem Spott des Hofs (Amm. 17,11,1: capella) und der störrischen Antiochener ausgesetzt, woraufhin dieser die Satire „Der Barthasser“ (Misopogon) als Erwiderung verfasste; vgl. DEMANDT ${ }^{3}$ (2007) 114; DEMANDT ²(2007) 126; ROSEN (2006) 14 f. u. 246f.; GIEBEL (2002) 156; DANGUILLIER (2001) 18.

132 Eugenius, der als Grammaticus bzw. Rhetor, obgleich er Christ war (Ambr. ep. 51 u. Soz. 7,22,4), dem paganen Bildungsgut nahestand, ließ sich als Kaiser mit dem „Philosophenbart“ darstellen; er arbeitete eng mit der heidnischen Senatsaristokratie Roms zusammen. Vgl. u.a. LEPPIN (2003) 206; GOLTZ (2002) 297-316, hier 302; DANGUILLIER (2001) 19; KLEIN (1971) 164 mit Anm. 60; HARTKE (1951) 240 u. 466.

133 Const. Sirm. 6 (9.7.425); CTh. 16,5,62 (17.7.425), CTh. 16,5,63 (4.8.425) und CTh. 16,5,64 (6.8.425). Ersichtlich wird die Vehemenz, mit welcher nun die ,Häretiker‘ verfolgt und harten Strafen ausgesetzt 
dämmte er die Vormachtstellung der Kirche ein, beraubte den Klerus seiner Privilegien und nahm ihnen das Recht der Gerichtsbarkeit, indem die kirchlichen Prozesse den weltlichen Gerichten unterstellt wurden. ${ }^{134}$ Mit solchen Maßnahmen und einer toleranten Haltung in Religionsfragen, die so schon Eugenius und Attalus an den Tag gelegt hatten, konnte sich Johannes gegen das streng orthodoxe theodosianische Kaiserhaus positionieren und zugleich das Wohlwollen heidnischer wie auch moderater christlicher Kreise der stadtrömischen Senatsaristokratie sichern.

Dennoch ist kaum ein prominenter stadtrömischer Aristokrat anzuführen, der in hoher Position das neue Regime unterstützt hätte. So fällt zwar die Prätur des Anicius Probus $^{135}$, dessen Vater Fl. Anicius Hermogenianus Olybrius ${ }^{136}$ bereits 395 das Konsulat bekleidet hatte, in die Zeit der Usurpation des Johannes ${ }^{137}$. Eine wie auch immer geartete Zusammenarbeit der gens Anicia darf hieraus jedoch nicht abgeleitet werden. Zumindest aber verwehrte sich dieses so bedeutende senatsaristokratische Geschlecht nicht gänzlich dem Usurpator und konnte sich wenigstens in Teilen mit den veränderten Verhältnissen arrangieren. ${ }^{138}$ Über die Besetzung der hohen Positionen in der Administration des Johannes durch Vertreter der stadtrömischen Senatsaristokratie lässt sich hingegen nur spekulieren. Ein infrage kommender praefectus Urbi wäre Iunius Valerius Bellicius ${ }^{139}$, der möglicherweise noch Ende 423 amtierte und eventuell das Amt auch weiter innehatte. Anicius Acilius Glabrio Faustus ${ }^{140}$, der sich im Hinblick auf seine spätere Karriere unter Valentinian III. wohl eher vom Usurpator ferngehalten hatte, kann hier wohl ausgeschlossen werden. ${ }^{141}$ Auch der praefectus prae-

werden. Auch wenn hierbei der Usurpator nicht eigens genannt wird, legt doch allein die Datierung nahe, dass diese Gesetze die maßvollen Anordnungen des Johannes außer Kraft setzen sollten. Vgl. hierzu bereits SEECK (1921) 408, Sp. 30; nachfolgend STICKLER (2002) 31f.; in Bezug auf die angeführten Gesetze vgl. KAISER (2007) 340; DEMOUGEOT (1988) 273-300, hier 286; OOST (1968) $191 \mathrm{mit}$ Anm. 82; GAUDEMET (1969) 129-147.

134 Const. Sirm. 6 (9.7.425); auch CTh. 16,2,46 (6.7. [4.8.] 425) und CTh. 16,2,47 (8.10 [6.8.] 425). Vgl. HARRIES/WOOD (1993) 154; SCHWEIZER (1991) 132f. u. 160; CIMMA (1989) 107-109.

135 PLRE 2, 911 (Probus 7).

136 Hierzu BLOCKLEY (1981) 220 Anm. 79; so auch SZIDAT (2010) 308 und NIQUET (2000) 136 gegen CAMERON (1984b) 193-196, der den Namen des Vaters auf Alypius korrigiert.

137 Olymp. fr. 41,2 (Blockley). Da Probus die Kosten von 1.200 Pfund Gold selbst bestreitet, ist anzunehmen, dass sein Vater Olybrius bereits verstorben war (wohl vor 410). Vgl. hierzu auch BLOCKLEY (1981) 220 Anm. 79.

138 Vgl. SZIDAT (2010) 308; STICKLER (2002) 31f.; bes. ZECCHINI (1983) 134 mit Anm. 30.

139 PLRE 2, 223. Vgl. CHASTAGNOL (1962) 289f. und ders. (1960) 245-247 (von Sep. 421 bis 423); dagegen aber MAZZARINO (1941) 361 (datiert CIL 6, 32085 auf 417); aktuell NIQUET (2000) 210 Anm. 69. 140 PLRE 2, 452-454; noch SIVAN (2011) 97 nimmt an, dass Faustus der PPO des Johannes gewesen sein könnte. Zu nahtlos anschließend erscheint seine weitere Laufbahn, die ihn bereits 425 als PVR zeigt, was wohl nicht der Fall gewesen wäre, wenn er als PPO des Usurpators amtiert hätte.

141 ZECCHINI (1983) 134 muss irren, dass Faustus als PVR des Johannes infrage käme, da Faustus gleich nach der Niederwerfung des Johannes schon am 17. Juli 425 das Amt unter Valentinian III. wieder innehatte und überdies in der Folgezeit einen beachtlichen Aufstieg erlebte (u. a. PVR 437; PPO 437/438 u. 442; Cos. 438). Vgl. CHASTAGNOL (1962) 286-289; nachfolgend auch SZIDAT (2010) 308 Anm. 1268. 
torio Italiae Proculus ${ }^{142}$, der als Amtsinhaber für den 18 . Mai 423 bezeugt ist, ${ }^{143}$ vermochte vielleicht weiter zu amtieren. Die Quellen hüllen sich allgemein in Schweigen, so dass es nahezu unmöglich ist festzustellen, in welchem Umfang der Usurpator mit der stadtrömischen Senatsaristokratie auf administrativer Ebene zusammenarbeitete. Auch hinsichtlich der Gesandtschaft, welche mit der Bitte um Anerkennung nach Konstantinopel abging $^{144}$, nennen die Quellen keine Namen, obgleich es zumindest naheliegt, dass Johannes hierfür namhafte Senatoren auswählte. ${ }^{145}$ Gemessen an dieser dürftigen Befundlage unterscheidet sich Johannes doch deutlich von Priscus Attalus. Was sich über die Münzprägung bereits andeutete, scheint sich nun zu bestätigen: Das Machtzentrum des Johannes ist in Oberitalien am ravennatischen Hof zu verorten und nicht in Rom im Kreis der Senatoren. Insofern kann zwar Johannes als ,senatsfreundlicher“ Kaiser, aber nicht als „Senatskaiser“ verstanden werden.

Umworben wurde die Senatorenschaft dennoch. Noch eine ganze Reihe von Gesetzen vom 6. August 423, die neun Tage vor dem Ableben des Honorius erlassen wurden und damit womöglich schon die Handschrift der künftigen Machthaber trugen, richtete sich in ganz altertümlich-ehrerbietender Form - consulibus, praetoribus, tribunis plebis, senatui suo salutem dicunt ${ }^{146}$ - an die gesellschaftliche und politische Führung Roms. Hiermit wurden die Privilegien der Senatoren bestätigt und sogar das iudicium quinquevirale ${ }^{147}$ wieder in seine alte Rechte eingesetzt. Die Vermutung Lütkenhaus', dass dies Ausdruck eines intensiven Werbens um den Senat und die stadtrömische Senatsaristokratie sei, lässt sich nicht von der Hand weisen. Nach dem Ende der Herrschaft des Honorius konnten der Senat und seine Senatoren durch diese Zugeständnisse, die im Übrigen auch die Machtmittel der Militärs beschnitten, ${ }^{148}$ an das neue Regime gebunden werden.

Für eine Amtszeit unter dem Usurpator Johannes würde sprechen, dass dieser nach dem Jahr 423 (425) nicht mehr in einem Amt $\mathrm{zu}$ fassen ist.

142 PLRE 2, 923 (Proculus 1).

143 Vgl. CTh. 13,6,10.

144 Socr. 7,23,3; Greg. Tur. Franc. 2,8; Theoph. a. m. 5915; Nic. Call. 14,7 und Philost. 12,13 (= Olymp. fr. 39,2 (Blockley)). Zu Senatoren im diplomatischen Einsatz (i. B. die patricii) vgl. MATHISEN (1986) $35-49$.

145 Philost. 12,13: Die Gesandten wurden sogleich an verschiedenen Orten der Propontis exiliert. Die Nähe des Exils zu Konstantinopel (Socr. 7,23,4) lässt vermuten, dass es sich hierbei um nicht ganz so unwichtige Persönlichkeiten handelte.

146 U.a. CTh. 1,6,11; CTh. 2,1,12; CTh. 4,10,2 oder CTh. 9,1,19. Vgl. LÜTKENHAUS (1998) 173 mit einer vollständigen Auflistung.

147 CTh. 2,1,12: in criminalibus causis senatus, statuta iam dudum quinqueviralis iudicii forma servabitur. Vgl. auch CTh. 9,1,13 (11.2. 376); ferner CTh. 1,28 u. 6,3,3; hierzu FLACH (1996) 358-376; ferner auch LIPPOLD (1963) Sp. 1162-1166 und COSTER (1935); zu dessen Bedeutungsverlust unter Constantius III. vgl. LÜTKENHAUS (1998) 149.

148 Dies i. B. dadurch, dass die executio militaris für Rom und Italien unterbunden wird; CTh. 1,6,11. Vgl. LÜTKENHAUS (1998) 173. 
Unberücksichtigt blieben bislang der ,starke Mann“ im Westen, der magister militum Castinus ${ }^{149}$ und sein Gegenspieler in Africa, Bonifatius ${ }^{150}$. Die Historiografen erkannten in der Mehrheit zwar nicht die Rolle des Castinus oder wussten nichts von ihm zu berichten, doch erscheint es sehr unwahrscheinlich, dass dieser nicht von Bedeutung gewesen sein sollte. Nur Prosper Tiro erwähnt ein verspätetes Mitwirken des Castinus. Hiernach soll er anfänglich zwar die Usurpation schweigend hingenommen, ${ }^{151}$ in Folge sich aber mit den Gegebenheiten gut abgefunden haben. ${ }^{152}$ Auf alle Fälle kann Johannes nicht gegen den Willen des führenden Militärs auf den Thron gekommen sein. ${ }^{153}$ Im darauffolgenden Jahr sollte Castinus dafür immerhin mit dem Konsulat belohnt werden. ${ }^{154}$ Johannes selbst verzichtete auf diese Ehre, obgleich es mittlerweile zur Gewohnheit geworden war, dass der neu erhobene Kaiser im Folgejahr seiner Erhebung das Konsulat ${ }^{155}$ für sich beanspruchte. Dass Castinus nach dem Sturz des Usurpators nicht dessen Schicksal teilte, sondern lediglich in die Verbannung geschickt wurde, ${ }^{156}$ spricht in erster Linie nur dafür, dass sich Castinus geschickt im Hintergrund gehalten hat. Castinus erhielt indes noch mehr durch Johannes. Denn nun hatte der magister militum einen Kaiser, der nicht zögern würde, den Eigenmächtigkeiten des Bonifatius ein Ende zu setzen. ${ }^{157}$ Insgesamt wird daher Seibel wohl zuzustimmen sein, dass das Verhältnis zwischen Johannes und Castinus nahe dem

149 PLRE 2, 269f. (Fl. Castinus 2).

150 PLRE 2, 237-240.

151 Diesbezüglich zieht BÖRM (2013) 65 die Möglichkeit in Betracht, dass Castinus aufgrund seiner Niederlage in Gallien gegen die Westgoten noch zu geschwächt gewesen sein könnte, als dass dieser selbst als Hauptakteur auftreten konnte. Der ,starke Mann` Castinus war möglicherweise zu diesem Zeitpunkt nicht so stark, wie man geläufig meint, und erhielt womöglich - gerade umgekehrt - in Johannes als Kaiser eine Stütze. Zum Kriegszug des Castinus vgl. HEATHER ${ }^{2}$ (2010) $310 \mathrm{f.}$

152 Prosp. Tiro 1280 (s. a. 423) (Chron. min. I. 470): Honorius moritur et imperium eius Iohannes occupat conivente, ut putabatur, Castino, qui exercitui magister militum praeerat. Vgl. hierzu SZIDAT (2010) 266; SEIBEL (2006) 114f.; STICKLER (2002) 29 mit Anm. 143; ZECCHINI (1983) $134 \mathrm{f}$.

153 So zuletzt auch SZIDAT (2010) 239: „Daß Iohannes einen Heermeister als Stütze benötigte, ist selbstverständlich.“ Vgl. SIVAN (2011) 90; HEATHER 2(2010) 303 hält Castinus sogar für den herausragendsten Unterstützer des Johannes. Vgl. SEIBEL (2006) 114-116; ELBERN (1984) 64.

154 CIL 5, 5206 und CIL 5, 6281 nennen selbigen als Konsul. Hier wird wohl von einer Ernennung durch Johannes ausgegangen werden können, zumal der Osten nur nach Victore v. c. consule zu datieren scheint; selbst das früheste Gesetz vom 9. Januar 424 CTh. 15,1,52 nennt nicht den westlichen Konsul Castinus. Gegen eine Ernennung zum Konsul durch Theodosius II. sprechen sich aus: SZIDAT (2010) 338; SEIBEL (2006) 114f.; BAGNALL (1987) 282f.; ebenso PLRE 2, 269f.; für eine Ernennung durch Theodosius II.: u. a. STICKLER (2002) 29 Anm. 141; STEIN (1959) 565 Anm. 152.

155 So Honorius (Mitkaiser seines Vaters 393: Cos. 394; Augustus des Westens 395: Cos. 396); Konstantin III. (Usurpator 407; in Arles 408: Cos. 409); Arcadius (Augustus des Ostens 395: Cos. 396); Theodosius II. (Mitkaiser 401: Cos. 402; Augustus des Ostens 408: Cos. 409); besonders auffällig bei Valentinian III. (Caesar 424: Cos. 425; Augustus des Westens 425: Cos. 426).

156 Prosp. Tiro 1290 (s. a. 425) (Chron. min. I. 471). Vgl. auch Ps.-Bonif. ep. 10, wonach Castinus zu Bonifatius floh, was allerdings aufgrund der Feindschaft eher unwahrscheinlich ist; hierzu CLOVER (1980) 73-95, hier 83-85 und DE LEPPER 1941, 28-30.

157 Prosp. Tiro 1278 (s. a. 422); Hyd. Lem. 78 (s. a. 421); Chron. Gall. 511 (s. a. 422). 
des Eugenius und Arbogast einzuordnen ist. ${ }^{158}$ Folglich spricht auch Heather von den Spitzen von Militär und Bürokratie, mit deren Unterstützung Johannes die Herrschaft ergreifen konnte, und weist Castinus die herausragende Position zu. ${ }^{159}$

Dem Senat und der stadtrömischen Senatsaristokratie ist dagegen nur eine sekundäre Bedeutung bei diesem ,Coup` beizumessen. Wird der Umstand richtig bedacht, dass die Usurpation in erster Linie im Interesse des Hofs und der hohen Militärs erfolgte, die sehr wohl angesichts der Übernahme der Herrschaft durch Konstantinopel oder einen von dort eingesetzten Kaiser zu befürchten hatten, dass entweder ihre Stellung obsolet werden könnte oder aber Konstantinopel sie durch eigene Leute ersetzen würde, ${ }^{160}$ ist deren Engagement in der Usurpation durchaus nachvollziehbar. Die stadtrömische Senatsaristokratie hatte durch die Oberherrschaft Konstantinopels weit weniger $\mathrm{zu}$ verlieren. Ihre Stellung und Bedeutung waren hierdurch nicht im Geringsten bedroht. Allenfalls der Senat als Gremium mochte vielleicht in Erwägung gezogen haben, wie sehr sich seine Möglichkeiten der Einflussnahme und Partizipation an der Herrschaft minimieren würden, wenn sich der Herrscher nur noch im fernen Konstantinopel aufgehalten hätte.

Prosper Tiro wusste hingegen von der bemerkenswerten cura des Johannes gegenüber Rom zu berichten, und komplettiert damit das beachtenswert positive Bild, welches sich in den Quellen findet:

In dieser Zeit wurde der Schutz des Johannes geschwächt, da er in einem Krieg Africa, das Bonifatius besetzt hielt, zurückforderte. ${ }^{161}$

Noch Seeck wollte hierin einen besonders edlen Zug des Johannes erkennen, der bewies, „dass er die Sicherheit seiner Untertanen über die eigene stellte“162. Doch nur die recht unzuverlässige Chronica Gallica von 452 erwähnt auch tatsächlich ein kriegerisches Vorgehen gegen Bonifatius, mit welchem Sigisvuldus ${ }^{163}$ beauftragt gewesen

158 Vgl. SEIBEL (2006) 115; ebenso SZIDAT (2010) 308; allerdings ist zu bemerken, dass Castinus es offensichtlich vermied, in der Außenwirkung eine gleichermaßen dominante Rolle wie Arbogast einzunehmen; als „Marionette“ darf Johannes nicht verstanden werden. Vorstellbar ist wohl eher eine Kooperation zwischen Militär und Hof; vergleichbar möglicherweise mit dem Bündnis zwischen dem PPO Jovius und dem magister equitum domesticorum Allobich. Vgl. LÜTKENHAUS (1998) 26.

159 HEATHER 2(2010) 303; zuvor auch LÜTKENHAUS (1998) 173 und MATTHEWS (1975) 379; nach-

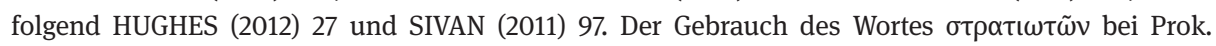
$B V$. 1,3,5 könnte der Bedeutung des Militärs Rechnung tragen, auch wenn es eine falsche Annahme bleibt, dass Johannes ein Offizier gewesen sei.

160 Vgl. STICKLER (2002) 34 und i. B. STEIN (1959) 282.

161 Prosp. Tiro 1286 (s. a. 424): Quo tempore Iohannes, dum Africam, quam Bonifatius obtinebat, bello reposcit, ad defensionem sui infirmior factus est. (= Paul. Diac. Hist. Rom. 13,9).

162 SEECK (1920) 91.

163 PLRE 2, 1010; hier wird zwar von einer Verwechslung ausgegangen mit dem Nordafrikazug von 428, doch gibt es gute Gründe dagegen zu argumentieren. Vgl. OOST (1968) 187 mit Anm. 68 oder DE LEPPER (1941) 43. 
sein soll. ${ }^{164}$ Es hatte sich jedoch schon mit Gildo und Heraclianus gezeigt, ${ }^{165}$ dass es für die Herrschaft im Westen, vor allem in Italien, von höchster Wichtigkeit war, die Kontrolle über die Kornkammer Africa auszuüben. ${ }^{166}$

Bei allen Spekulationen, die bis hierhin angestellt werden können, steht fest, dass die Rechnung mit den vielen unbekannten Variablen nicht aufging. Dass Theodosius II. die Wahl des Senats nicht achten würde und stattdessen für seine westliche Verwandtschaft den Krieg befahl, war zwar nicht ausgemacht, aber doch einzukalkulieren. Erwartungsgemäß verweigerte Bonifatius den Gehorsam. Dass nun aber die Diözese dem comes Africae, der diese Stellung selbst mehr okkupiert als rechtmäßig erworben hatte, ${ }^{167}$ die Treue halten würde und nicht Rom und seinem durch den Senat legitimierten Kaiser, war die erste ernste politische Niederlage für das Regime des Johannes. ${ }^{168}$ Auch die nach Gallien entsandten Beamten hatte ein gewaltsamer Tod ereilt ${ }^{169}$ und nun machten sich noch die Westgoten ${ }^{170}$ das Chaos zunutze. Die Autorität und Weisungsgewalt des Usurpators blieben somit weitestgehend auf Italien beschränkt. In der Folge steht der letzte Akt dieser Usurpation unter dem Zeichen der allgemeinen Auflösung. Kampflos öffneten sich die Tore Ravennas dem oströmischen Expeditionsheer und die Verteidiger lieferten ihren Kaiser aus. ${ }^{171}$ Auf dem Rücken eines Esels im Circus von Aquileia dem Spott der schaulustigen Menge ausgesetzt, ${ }^{172}$ endete die Herrschaft des vom Senat erwählten Kaisers. ${ }^{173}$

164 Chron. Gall. 96 (s. a. 424). Vgl. STICKLER (2002) 31 mit Anm. 151 merkt an, dass statt Sigisvuldus auch Castinus den nordafrikanischen Kriegsschauplatz kommandiert haben könnte; zumal dieser weder in Norditalien noch in Gallien an Kampfhandlungen beteiligt gewesen zu sein schien (vgl. Prosp. Tiro 1286, s. a. 424 und Chron. Gall. s. a. 425). Von Sigisvultus ist hingegen bekannt, dass dieser noch unter Valentinian III. in der hohen Position des vir inlustrissimus magister militum (Nov. Val. 9 (a. 440)) war, was eine enge Verbindung mit dem Usurpator unwahrscheinlich werden lässt. Vgl. MCEVOY (2013a) 262; HUGHES (2012) 67 f. und bes. MATHISEN (1999) 173-196, bes. 184-186.

165 Vgl. Kap. 4.1, Kap. 5.1 und Kap. 5.2.

166 Wie dies für Johannes zutraf, galt es auch für jeden Kaiser oder Reichsverweser, den Konstantinopel einsetzen mochte; so vollkommen richtig SEIBEL (2006) 115 Anm. 782. Vgl. zum Bündnis zwischen Galla Placidia und Bonifatius vgl. SEIBEL (2006) 113f.; SIVAN (2011) 90 u. 105-108; STICKLER (2002) 28f. und LÜTKENHAUS (1998) 170-172; zur Legitimierung der Stellung des Bonifatius vgl. DIESNER ${ }^{2}$ (1963) $100-126$, bes. 108 und DE LEPPER 1941, 38 f.

167 Prosp. Tiro 1278 (s. a. 422); Hyd. Lem. 78 (s. a. 421); Chron. Gall. 511 (s. a. 422). Vgl. hierzu SEIBEL (2006) 113f. und STICKLER (2002) 28; LÜTKENHAUS (1998) 170-172; gegen eine „Usurpation“ der comitiva Africae durch Bonifatius im Jahr 422 spricht sich aus PARONETTO (1975) 405-452, hier 405, Anm. 1.

168 Prosp. Tiro 1286 (s. a. 424).

169 Prosp. Tiro 1286 (s. a. 424). Vgl. Chron. Gall. 452,97 (s. a. 425); PLRE 2, 448 (Exuperantius 2) und LÜTKENHAUS (1998) 111.

170 Ebd. Vgl. hierzu auch STICKLER (2002) 32 mit Anm. 156; COULON (2000) 42 mit Anm. 55; ZECCHINI (1983) 136 (allerdings sehr spekulativ); OOST (1968) 186f. und SIRAGO (1961) $247 \mathrm{f}$.

171 Olymp. fr. 43,2 (Blockley) und Philost. 12,13. Vgl. auch Prosp. Tiro 1290 (s. a. 425); Hyd. Lem. 86 (s. a. 425); Theoph. a. m. 5916 und Socr. 7,24. Hierzu vgl. OOST (1968) 189 und STEIN (1959) 284.

172 Prok. BV. 1,3,9.

173 Olymp. fr. 43,1f. (Blockley) und Philost. 12,14. 
Als „Erwählter des Senats“174 zu gelten, verschaffte Johannes in keiner Weise einen sichereren Stand. Die Autorität des Senats reichte nicht aus, das Zweckbündnis zwischen der ravennatischen Zivilbeamtenschaft und dem Militär zu stabilisieren. Schon bei der ersten sich bietenden Gelegenheit wurde dem dynastischen Prinzip der Vorrang gegeben und die Soldaten übertrugen lieber „dem Valentinianus, der noch ein Kind war, die Kaiserherrschaft“"175, als noch länger einem Kaiser die Treue zu halten, der als erfahrener Zivilbeamter mit Billigung des Senats die Herrschaft ausübte. Einmal mehr zeigt sich hierin die mangelnde gravitas und auctoritas des Senats und sein Unvermögen, auch im Ernstfall eine Stütze für die Kaiserherrschaft darstellen zu können.

\subsection{Petronius Maximus - ein Senator auf dem Kaiserthron?}

Erstmals 1983 befasste sich Czúth ausführlicher mit Petronius Maximus. ${ }^{176}$ Die zentrale Frage war dabei noch, ob und inwiefern dieser als „Kaiser der (italischen) Senatsaristokratie“177 oder auch des Senats gelten kann. Czúth, wie auch nachfolgend Henning und Szidat, sprachen sich zumindest insofern dagegen aus, als dass sie weder die Senatsaristokratie Italiens noch die senatorischen Häuser Roms oder aber den Senat als Machtbasis des Petronius Maximus verifizieren konnten und überdies sich scheinbar auch keine besonders enge Zusammenarbeit fassen ließ. ${ }^{178}$ Szidat ordnete ihn eher in die Reihe der „zivilen Usurpatoren“179 ein und vermied eine Bezeichnung als „Senatskaiser“180, wie sie noch von Demandt und Mazzarino verwendet wurde. Die Einwände Czúths und Szidats sind wohl berechtigt. Nichtsdestotrotz lässt es sich wohl kaum übersehen, dass der Senat und zumindest Teile der stadtrömischen Senatsaristokratie bei jeder in Italien stattfindenden Usurpation der vergangenen sechzig Jahre direkt oder indirekt beteiligt gewesen waren; so eben auch im Fall des Petronius Maximus.

Dass dieser hier folgerichtig in die Reihe der Usurpatoren ${ }^{181}$ eingeordnet wird, begründet sich aus der Tatsache, dass seine Herrschaft in Konstantinopel keine Anerkennung fand. Als die Mörder Valentinians am 16. März 455 dem - wie sich Seeck

174 SEECK (1920) 95.

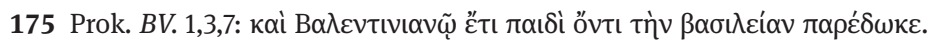

176 CZÚTH (1983) 253-258.

177 So noch PIGANIOL ${ }^{4}$ (1954) 506 [1939] und STROHEKER (1954) 68-75, hier 71.

178 Vgl. CZÚTH (1983) 254; nachfolgend SZIDAT (2010) 264 Anm. 1058 und HENNING (1999) 272.

179 Vgl. SZIDAT (2010) 267.

180 Vgl. MEIER (2019) 473; DEMANDT (2013a) 69 [1980]; nachfolgend ders. ${ }^{2}$ (2007) 331; auch MAZZARINO (1980) 804f.; dagegen SZIDAT (2010) 184.

181 So Marcell. Com. s. a. 455 (= Chron min. II. 86): Idem Maximus invasit imperium tertioque tyrannidis suae mense membratim Romae a Romanis tractus discerptusque est. Vgl. Iord. Get. 235; Iord. Rom. 334; Prok. BV. 1,4,36; Mal. 14,44; Theoph. a. m. 5947; für weitere Belegstellen vgl. HENNING (1999) $193 \mathrm{f}$. Anm. 28, der auch glaubhaft darlegen konnte, dass Marcian diesen als tyrannus betrachtete. 
ausdrückte - „Vornehmsten unter den Senatoren“ Pferd und Diadem „,ihres kaiserlichen Opfers“"182 anboten, war der Senat von der Herrschaft so weit entfernt wie ehedem. Über die Nachfolge Valentinians entschied Ansehen, Einfluss und nicht zuletzt das Geld. ${ }^{183}$ An dignitas kam dem zweifachen Konsul (433/443) und patricius (445), ${ }^{184}$ der schon in jungen Jahren als tribunus et notarius und comes sacrarum largitionum amtierte und zweimal die Stadtpräfektur und Prätorianerpräfektur Italiens innehatte, ${ }^{185}$ keiner gleich. Zwischen der ersten und zweiten Amtszeit als praefectus Urbi wurde Petronius Maximus sogar eine Ehre zuteil, die sonst in seiner Zeit nur Persönlichkeiten wie Stilicho, Fl. Constantius oder Aëtius zuerkannt worden war. ${ }^{186}$ Mit einer goldenen Ehrenstatue ${ }^{187}$ auf dem Forum Romanum, unweit der Curia, ehrte der Senat diesen und reihte ihn damit ein in den erlauchten Kreis solch hochgepriesener Senatoren wie Vettius Agorius Praetextatus ${ }^{188}$. Ferner wären weitere Ehrenmonumente auf dem Trajansforum ${ }^{189}$ und seinem privat gestifteten forum ${ }^{190}$ anzuführen. So dürfte Zecchini nicht ganz falsch liegen, wenn er vermerkt, dass im Jahr 455 dieser keine echten Konkurrenten hatte, ${ }^{191}$ die entsprechend prädestiniert gewesen wären, die Kaiserwürde zu beanspruchen.

Wenn hierbei nicht ganz sicher ist, dass Petronius Maximus als Anicier anzusprechen ist, so liegt dies an der generellen Schwierigkeit, die gens Anicia in ihrer Gesamtheit zu erfassen. Hinzu kommt das Problem, dass für Petronius Maximus,

182 SEECK (1920) 321.

183 SZIDAT (2010) 128 weist hingegen den „Bestechungsvorwurf“, den Prisk. fr. 30,1 (Ioh. Ant. fr. 201,6 und Hyd. Lem. 162 (s. a. 455)) vorbrachte, als Topos zurück; eine Zahlung an die Offiziere schließt er jedoch nicht aus; HENNING (1999) 20 und CZÚTH (1983) 254 heben hingegen die Bedeutung der Bestechung hervor.

184 Hierzu vgl. BARNES (1975) 156-158.

185 Zur Ämterlaufbahn vgl. HENNING (1999) 28-32, bes. 29 mit leichter Abweichung von WEBER (1989) 480 f.; CZÚTH (1983) 254; PLRE 2, 749 (Maximus 22) und SEECK (1920) 332. Zur Ebenbürtigkeit gegenüber den großen Vorfahren vgl. CIL 6, 1749 (ILS 809; Trajansforum): CVIVS A PROAVIS ATABISQ(ue) NOBILITAS PARIB(us) TITVLORVM INSIGNIB(us) ORNATVR [...]; zum jungen Eintrittsalter ebd.: PRIMAEVS IN CONSISTORIO SACRO TRIBVNVS ET NOTARIVS MERVIT NONO DECIM $(o)$ AETATIS ANNO [...]; zur Länge der Amtszeit ebd.: SACRARVM REMVNERATIONVM PER TRIENNIVM COMES [...] PRAEFECTVS VRBI ANNO ET SEX MENSIB(us). Vgl. zu den Inschriften und der Darstellung von Einzelleistungen NIQUET (2000) 143f. Zur Bedeutung der dignitas in der Usurpation vgl. SZIDAT (2010) $184 \mathrm{f}$.

186 Stilicho: CIL 6, 1730, 1731 und CIL 6, 41381; Fl. Constantius: CIL 6, 1719 (?) und CIL 6, 1720; Aëtius: CIL 6, 41389. Zu den auf dem Forum Romanum aufgestellten Ehrenstatuen vgl. NIQUET (2000) 20 - 24, 52 u. 72 und PANCIERA (1996) 277-297.

187 CIL 6, 41398: in der Ergänzung der Dedikationsformel nach PANCIERA (1996) 294: STATVAM SVB AVRO FVLGENTEM ERIGI CONLOCARIQVE IVSSERVNT. Vgl. auch CHENAULT (2012) 124-129 und MACHADO (2006) 173-179.

188 PLRE 1, 722-724; hier CIL 6, 1779a. Vgl. NIQUET (2000) 179 u. bes. $238 \mathrm{f}$.

189 CIL 6, 1749 (ILS 809). Vgl. NIQUET (2000) $143 \mathrm{f}$.

190 CIL 6, 1197 u. 1198. Vgl. ausführlich hierzu Kap. 8.4.

191 ZECCHINI (1983) $127 \mathrm{f}$. 
anders als etwa für Olybrius, der Gentilname Anicius ${ }^{192}$ nicht überliefert ist. Neben Probus, Olybrius ${ }^{193}$ und Symmachus, nennt Olympiodor allerdings einen gewissen Maximus, der in der Forschung mit Petronius Maximus identifiziert wird. ${ }^{194}$ Da Olympiodor hier prominente Anicier nennt, wurde auch der genannte Maximus zu diesen gezählt. ${ }^{195}$ Stichhaltig ist dies jedoch nicht. Mehr Gewicht fällt da der genealogischen Verbindung zwischen Fl. Maximus, dem Konsul von 523, und Petronius Maximus, die Prokop überliefert, $\mathrm{zu}^{196}$ Dabei ist es vollkommen unerheblich, dass diese Verbindung wahrscheinlich rein fiktiv ist. Da Fl. Maximus bei Cassiodorus als Angehöriger der gens Anicia überliefert ist, ${ }^{197}$ wird damit Petronius Maximus eindeutig mit den Aniciern in Verbindung gebracht. Zusammen mit der Accusatio Xysti papae ${ }^{198}$ von 501, lässt sich zumindest feststellen, dass Petronius Maximus Anfang des 6. Jhs. als Angehöriger der gens Anicia angesehen wurde. Seine genaue Abstammung bleibt dennoch unklar. ${ }^{199}$ Dieser schwierige Befund birgt aber auch eine Erkenntnis. Offen-

192 Die Namensform Flavius Anicius Petronius Maximus, die in der älteren Literatur und gelegentlich auch in neueren englischsprachigen Beiträgen Verwendung findet, besitzt keine Quellengrundlage. 193 Probus 7 = 2 (vermutlich Sohn des Anicius Hermogenianus Olybrius 2); nach BLOCKLEY (1981) 220 Anm. 79; so auch SZIDAT (2010) 308 und NIQUET (2000) 136 gegen CAMERON (1984b) 193-196, der den Namen des Vaters auf Alypius korrigiert.

194 Olymp. fr. 41,2 (Blockley) nennt die Summe von 4.000 Pf. Gold für die Spielgebung; vgl. hierzu JONES (1964) 577f. Zur Identifizierung der Person vgl. CAMERON (1984b) 193-196 und ders. (1999b) 477-505; zusammenfassend zur Forschungsdiskussion HENNING (1999) 28f. Von Petronius Maximus gehen eine Vielzahl von Forschern aus: u. a. BEYELER (2011) 39; LANCON (2001) 143; NIQUET (2000) 137; MITTAG (1999) 83 mit Anm. 72; KRAUSE (1987) 321; wobei sich etwa DEMANDT 2(2007) 205 und CLOVER (1983) 128 für Petronius Maximus und dessen Sohn Palladius aussprechen und PLRE 2, 749 (Maximus 22) für Petronius Maximus und seinen gleichnamigen Vater.

195 Vgl. HENNING (1999) 29. Dass Olympiodor hier „sonst nur prominente Anicier aufzählt“ ist eine falsche Aussage. Quintus Aurelius Symmachus ist kein Anicier. Allerdings besteht eine familiäre Verbindung zwischen den Symmachiern und den Aniciern (Aurelius Anicius Symmachus 6).

196 Prok. BG. 1,25,15. An anderer Stelle behauptet Prokop auch eine Abstammung des Petronius Maximus von dem Usurpator Magnus Maximus (383-388); vgl. Prok. BV. 1,4,16; nachfolgend auch Theoph. a. m. 5947 und Georg. Cedr. 605. Hier ist natürlich der Name Maximus ausschlaggebend für die genealogische Verbindung.

197 Cassiod. Var. 10,11,2. Maximus 20 (PLRE 2, 748-749).

198 Petronius Maximus als Verteidiger Sixtus' III. entsprechend der Rolle des Fl. Anicius Probus Faustus iunior Niger im Laurentianischen Schisma. Vgl. HENNING (1999) 119 mit Anm. 12; ausführlich WEBER (1986) 478f. u. 486-488 und ZECCHINI (1980) 64-70. Zum Laurentianischen Schisma u.a. WIRBELAUER (1993); MOORHEAD (1992) 114-139 und SCHÄFER (1991) 212-239.

199 Vgl. HENNING (1999) 29-33 und MOMMAERTS/KELLEY (ND 2002) 111-121 mit Fig. 10.1 [1992]. Die von MOMMAERTS und KELLEY vorgeschlagene Einbindung des Petronius Maximus in die gens Anicia erscheint höchst spekulativ und kann so vor allem hinsichtlich der mutmaßlichen Söhne des Petronius Maximus nicht hinkommen. Neben Palladius sollen hiernach auch Anicius Olybrius 6 (Aug. 472) und Magnus (Cos. 460) Söhne des Maximus gewesen sein. Der Konflikt bzw. Konkurrenzkampf zwischen Olybrius 6 und Petronius Maximus passt hierzu aber kaum; so auch schon von GILLETT (2003) 88 Anm. 11 zurückgewiesen. In Fl. Anicius Probinus 1 (Cos. 395) den Vater des Petronius Maximus zu sehen, ist umso unwahrscheinlicher, falls dessen Frau Italica eine Schwester des Symmachus war; weder zu den Symmachi (Aur. Anicius Symmachus?) noch zu Probinus 1, Italica oder Anicia Italica 2 
sichtlich war der Verweis auf die gens Anicia für Petronius Maximus nicht so zentral. Weder lässt sich erkennen, dass Petronius Maximus eine wie auch immer geartete „Politik“ der Anicier betrieb, noch lässt sich die gens Anicia als politische Größe fassen. Die enorme finanzielle Potenz, die große Klientel und vor allem das hohe Ansehen, welches die Nachkommen des Sextus Claudius Petronius Probus vor dem theodosianischen Kaiserhaus besaßen, können den schnellen, schon in jungen Jahren vollzogenen Aufstieg des Petronius Maximus erklären. Zur höchsten Spitze gelangt Petronius Maximus aber als überragende Einzelpersönlichkeit und als solche wurde er letztlich auch wahrgenommen.

Trotz der herausragenden Stellung des Petronius Maximus war die Erhebung zum Kaiser jedoch nur durch eine Übereinkunft mit Majorian ${ }^{200} \mathrm{zu}$ erreichen. Immerhin kommandierte dieser die protectores domestici, welche den einzig relevanten militärischen Machtfaktor am Hof darstellten und für die Kaiserakklamation ${ }^{201}$ unentbehrlich waren. Der aus der gallischen Senatsaristokratie stammende Eparchius Avitus, ${ }^{202}$ der nachfolgend selbst die Kaiserwürde für sich beanspruchen sollte, wurde als magister militum ${ }^{203}$ eingesetzt. Avitus sollte wohl die in Gallien stationierten Truppen im Gehorsam halten und mittels seines diplomatischen Geschicks die Bedrohung durch die Westgoten und Alanen eindämmen. ${ }^{204}$ Vielleicht sollte auch das unter Aëtius geschmiedete Militärbündnis ${ }^{205}$ erneuert werden, was insofern von be-

lässt sich eine Verbindung herstellen. Sollte Petronius Maximus zur Nachkommenschaft des Sex. Petronius Probus zählen, käme als Vater am ehesten Fl. Anicius Petronius Probus 11 (Cos. 406) infrage. Probus 11 war im Jahr 395 evtl. 12 Jahre (quaestor candidatus; CIL 6, 1752), zur Zeit seines Konsulats demnach ca. 23 Jahre. Folglich liegt es im Bereich des Möglichen, dass Maximus um 400 als Sohne des Probus 11 geboren wurde. Sollten überdies Probus 11 und Probus 1 (CSL 412-414) identisch sein, wäre Petronius Maximus seinem Vater 416 mit 16 Jahren im Amt des CSL gefolgt. Den nötigen politischen Support hätten Olybrius 2 und Probinus 1, die sich aus dem Staatsdienst spätestens 397 zurückgezogen haben, wohl nicht leisten können - evtl. aber Prous 11 (= Probus 1?).

200 Dieser galt sogar selbst als Anwärter und wurde unterstützt durch die Kaiserinwitwe Licinia Eudoxia; vgl. Prisk. fr. 30,1; Ioh. Ant. fr. 201,6. Zur Kandidatur vgl. auch Sid. carm. 5,312-314. Offensichtlich verblieb Majorian in der Position des comes domesticorum, die er noch beim Sturz des Avitus innehatte (Chron. Gall. 628). Vgl. HENNING (1999) 73. Da Avitus als präsentabler Heermeister in Gallien eingesetzt wurde, jedoch nicht den Patriziustitel erhielt, wäre die Vergabe bzw. das Versprechen dieser Würde denkbar. Vgl. HENNING (1999) 72; DEMANDT (1970) Sp. 672 u $681 \mathrm{f}$. und ENSSLIN (1931) 467502, hier 489.

201 Vgl. SZIDAT (2010) 126-130; 245 („Wahlversammlung“) und 266, wobei ebd. 348 die Bedeutung des Hofs und der zivilen Amtsträger betont.

202 PLRE 2, 196 -198 (Eparchius Avitus 5). Vgl. ausführlicher MATHISEN (1981) 232-247.

203 Sid. carm. 7,376-378.

204 Sid. carm. 7,388-392. Vgl. auch Sid. carm. 2,400-402. Das Operationsgebiet des Avitus umfasst ausschließlich Gallien, was nahelegt, dass dieser nicht als magister utriusquae militiae das Kommando über das italische Feldheer (exercitus Italiae) ausübte. Vgl. HENNING (1999) 33f. Jedoch amtierte als magister militum per Gallias seit 452 Agrippinus. Vgl. HENNING (1999) 72f. Zum panegyricus auf Avitus vgl. GILLETT (2003) 84-108.

205 Zur Rolle des Avitus vgl. WOLFRAM (1990) 182f. oder LOYEN (1963) $440 \mathrm{f}$. Dass hier eine Allianz gegen die Vandalen in Africa geschmiedet werden sollte ist denkbar, wenn auch nicht belegbar. Vgl. 
sonderer Relevanz war, falls Petronius Maximus eine militärische Lösung des Vandalenproblems anstrebte. Dies wiederum könnte das maßgebliche Bedrohungsszenario $^{206}$ für Geiserich gewesen sein, welches ihn letztlich zu einem schnellen, präventiven Erstschlag gegen Rom zwang.

Die Umstände der Kaisererhebung und insbesondere die Beratung hierüber offenbart, dass in erster Instanz Vertreter des Hofs $^{207}$ und des Militärs hierüber entschieden. Der Senat hatte hieran zunächst keinen Anteil, auch wenn davon auszugehen ist, dass wichtige Vertreter der stadtrömischen Senatsaristokratie am Hof präsent ${ }^{208}$ waren. All diese mochten zu dem Entschluss gekommen sein, „Maximus könne dem gefährdeten Imperium nützen“209. Sowohl seine Erfahrung im kaiserlichem Dienst, welche ihn einst sogar als praeceptor (Erzieher) ${ }^{210}$ Valentinians III. empfahl, als auch seine edle Abstammung und die weit ausgreifenden Kontakte, ${ }^{211}$ die geeignet schienen, das auseinanderdriftende Reichsgefüge zusammenzuhalten, mochten dem Reich in der Tat genauso dienlich erscheinen wie das immense Privatvermögen des Petronius Maximus, welches nun in das kaiserliche patrimonium $^{212}$ einfloss. Das mit Abstand größte Problem für Petronius Maximus stellte die mangelnde Legitimation dar. Eigenmächtig, ohne den Vorrang des senior Augustus und nominellen Alleinherrschers des Imperiums zu achten, ${ }^{213}$ erhoben die Führungsgruppen am westlichen Hof und im Heer einen eigenen Kaiser. Vergleichbar mit der Situation des Usurpators Johannes sollte gewiss auch im Jahr 455 der Senat von Rom

GILLETT (2003) 84-108, bes. 88f. u. 96-104; HENNING (1999) 22-24 hier deutlich gegen die Hypothesen CLOVERs argumentierend; CLOVER (1966) $147 \mathrm{f}$. Zum Vandalenreich in Nordafrika vgl. aktuell VÖSSING (2018); ders. (2015) u. (2014) und STEINACHER (2016).

206 Die Westgoten sind als erbitterte Feinde der Vandalen zumindest der natürliche Bündnispartner. Die Feindschaft resultiert aus der Aufhebung der Ehe zwischen Hunerich und der ältesten Tochter Theoderichs I., die verstümmelt an Nase und Ohren ihrem Vater zurückgesandt wurde; Iord. Get. 185 und Prisk. fr. 20,2. Hierzu vgl. allgemein VÖSSING (2018) 44-89; ders. (2014) 50-110; i. B. ders. (2015) 11-38; ferner KAMPERS (2008) 128 und STICKLER (2002) 236.

207 Die Beteiligung des Hofs wird deutlich an der Mitsprache der Kaiserinwitwe Licinia Eudoxia sowie der Beteiligung des Majorian. Vgl. SZIDAT (2010) $128 \mathrm{f}$.

208 Dass sie hierzu nicht zwingend auch ein Amt bekleiden mussten, lässt sich an Petronius Maximus selbst exemplifizieren; so auch SZIDAT (2010) 128.

209 Prosp. Tiro 1375 (s. a. 455): Maximus [...]. Qui cum periclitanti rei publicae profuturus per omnia crederetur; ähnlich Sid. carm. 2,13.

210 CIL 6, 41398. Vgl. hierzu NIQUET (2000) 61; PACK (1997) 400 und CRACCO RUGGINI (1988) 62-85, hier $81 \mathrm{f}$. mit Anm. 33.

211 Namentlich lässt sich ein Klient (Sid. ep. 2,13,1-4: patrocinia florebant) fassen: Serranus (PLRE 2, 996). Vgl. HENNING (1999) 74 oder KRAUSE (1987) 10.

212 Diesbezüglich ist auch die erstaunlich hohe Zahl an Goldprägungen (gemessen an der kurzen Regierungszeit) hervorzuheben. Vgl. HENNING (1999) 120: „Goldschwemme“.

213 Wie sehr Petronius Maximus auf die Anerkennung durch Konstantinopel hoffte, belegt auch die Münzprägung mit dem Verweis auf beide Augusti: VICTORI-A AVGGG. (RIC 10, 2201-2203). 
diesen legitimatorischen Makel ausgleichen. ${ }^{214}$ Wahrscheinlich bestätigten die patres conscripti hierbei lediglich die bereits entschiedene Kaiserwahl und kamen damit ihrer formalen Aufgabe, in der Außenwahrnehmung als auctores imperii und Legitimationsbasis zu erscheinen, nach. ${ }^{215}$

Ein weiterer schwerwiegender Punkt, dem es zu begegnen galt, war das Aussterben der valentinianisch-theodosianischen Dynastie ${ }^{216}$ in der männlichen Linie. Wie sich Börm treffend ausdrückte, fiel mit dem Tod Valentinians III., „die Loyalität der Reichsbevölkerung gegenüber dem altehrwürdigen Kaiserhaus fort, und mit ihr das stärkste einigende Band, über das das Imperium Romanum angesichts seiner fortschreitenden Desintegration noch verfügt hatte. ${ }^{\text {(217 }}$. Dem versuchte Petronius Maximus entgegenzuwirken, indem er die Ehe mit der Kaiserinwitwe Licinia Eudoxia einging ${ }^{218}$ und seinen Sohn Palladius wohl mit der jüngeren Tochter Valentinians III., Placidia, vermählte. ${ }^{219}$ Ein solcher Schritt war zweckdienlich, wenn es darum ging, stabile Verhältnisse zu erhalten. In ähnlicher Weise hatte auch Pulcheria durch die Eheschließung mit Marcian die Herrschaft der theodosianischen Dynastie im Osten über das Jahr 450 hinaus immerhin nominell erhalten können. ${ }^{220}$ Umso irritierender muss es dabei erscheinen, dass Petronius Maximus mit diesem Vorgehen offenbar auf

214 SZIDAT (2010) 290f. erkannte vollkommen zu Recht die Bedeutung des Senats als zusätzliche Legitimationsbasis, die insbesondere wichtig war, wenn Konstantinopel seine Zustimmung versagte. Vgl. auch HENNING (1999) 272-274.

215 Sidonius Apollinaris bezieht sich zwar in seinen Preisreden nicht auf Petronius Maximus, dem er überdies aufgrund seines schmachvollen Endes eher verhalten gegenüberstand (Sid. carm. 7,556f.), konnte aber seinen Kaiser Avitus ebenso noch als publicus pater $(6,35)$, der nichts Besseres als den Senat an seiner Seite hat (Sid. carm. 7,503), preisen. Vgl. GÜNTHER (1983) 654-673, hier 655. Im Fall des Libius Severus vermerkt Hyd. Lem. 211: Severus a senatu Romae Augustus appellatur. Von SEECK (1920) 91, 339, 349 u. 482 wird die Einflussmöglichkeit des Senats als „Wahlorgan“ bei der Inthronisierung des Johannes, Majorian und Libius Severus hingegen deutlich zu hoch eingeschätzt. Vgl. SZIDAT (2010) 252-255 mit Anm. 1008.

216 Vgl. Prisk fr. 30,1, 58 - 71.; das Erlöschen der Dynastie hält so auch Hyd. Lem. 157 (s. a. 455) fest.Vgl. BÖRM (2013) 89; ausführlich SCHARF (1996a) 5-25.

217 BÖRM (2013) 93.

218 Prosp. Tiro 1375 (s. a. 455): Augustam amissionem viri lugere prohibitam intra paucissimos dies in coniugium suum transire coegerit. Vgl. auch Hyd. Lem. 167 (s. a. 455); Prisk. fr. 30,1 (= Ioh. Ant. fr. 201,6); Euagr. Hist. eccl. 2,7; Prok. BV. 1,4; Theoph. a. m. 5947. Vgl. zu weiteren Belegen HENNING (1999) 30 Anm. 17.

219 Hyd. Lem. 167 (s. a. 455): [...] et filio suo ex priori coniuge Palladio, quem Caesarem fecerat, Valentiniani filiam in coniugium tradidisset. CLOVER (1978) $180 \mathrm{f}$. konnte die nicht namentlich genannte Tochter schlüssig mit Placidia identifizieren, da Eudocia wohl weiterhin dem Hunerich versprochen war; zum Vertrag von 442 vgl. SCHULZ (1993) 92-95 oder CLOVER (1973) 104-117, hier 107f.; dem folgt auch HENNING (1999) 30 und CZÚTH (1983) 254; vormals bereits auch CAPIZZI (1968) 191-226, hier 199f. BÖRM (2013) 96; CAMERON (2012) 165; SZIDAT (2010) 129 und HEATHER ²(2010) 436 nehmen hingegen noch die ältere Tochter Eudocia an (gemäß PLRE 2, 407).

220 Vgl. SZIDAT (2010) 129. 
erheblichen Widerstand ${ }^{221}$ stieß. Entgegen der Vorstellung Seecks ${ }^{222}$ wird weniger die Pietätlosigkeit, die trauernde Witwe so rasch geehelicht zu haben, hierbei von Bedeutung gewesen sein. Selbst wenn Petronius Maximus die Augusta hierzu tatsächlich genötigt haben sollte, ${ }^{223}$ war dies bei Weitem nicht so kritisch wie die Vermählung zwischen Palladius und Placidia. Denn an dieser Verbindung müssen gleich zwei wichtige Persönlichkeiten Anstoß genommen haben. Zum einem war da Majorian, dem bereits um 450 Placidia versprochen worden war ${ }^{224}$ und der vermutlich noch immer der Favorit der Augusta war. Zum anderen war da noch immer Anicius Olybrius, dem zuletzt von Valentinian III. 454 die Hand der Kaisertochter angeboten worden war. Diesen überging Petronius Maximus ebenfalls.

Kurz vor der Erhebung des Petronius Maximus hatte es Olybrius vorgezogen, Rom in Richtung Konstantinopel zu verlassen. ${ }^{225}$ Es ist aber davon auszugehen, dass seine Anhängerschaft noch weiterhin in der Stadt präsent war. Die Stadtbevölkerung aufzuwiegeln, indem die Rohheit und Pietätlosigkeit des Usurpators propagiert wurde ${ }^{226}$, mochte hierbei ein probates Mittel sein, den Sturz des Petronius Maximus zu beschleunigen. Olybrius, der mit Sicherheit am Verlöbnis festhielt, ${ }^{227}$ hatte überdies auch die Möglichkeit, am Hof in Konstantinopel gegen die Anerkennung des Petronius Maximus zu intervenieren. So ist es wohl auch kein Zufall, dass gerade die oströmischen Geschichtsschreiber, wie Johannes von Antiochia, Euagrios, Theophanes und Prokop, von den größten Schändlichkeiten des Petronius Maximus in ganzer Breite zu berichten wussten. ${ }^{228}$

221 Sid. ep. 2,13,5: [...] ipsam aulam turbulentissime rexit, inter tumultus militum, popularium, foederatorum. Hyd. Lem. 162 (s. a. 455): [...] in ips a urbe tumultu populi et seditione occiditur militari. Zu diesen Gruppen, die im Übrigen die maßgeblichen Akzeptanzgruppen (FLAIG 1997, 15-35) Heer, Hof, Senatsaristokratie (Senat) und plebs umfassen, vgl. CZÚTH (1983) 256.

222 SEECK (1920) 323.

223 Zur Diskussion auf Grundlage von Prok. BV.1,4,28f. vgl. MOORHEAD (1994) 83 oder JONES (1964) 240; hinsichtlich seiner politischen Bedeutung als „Heiratsprojekt“ zur Stabilisierung der Herrschaft, unter kritischer Auseinandersetzung mit dem stereotypen und vorurteilsbehafteten Frauenbild des Prokop, vgl. SCHÄFER (2006) 275-294, bes. 276.

224 Vgl. Sid. carm. 5,204-206 u. 5,293-304. Vgl. HENNING (1999) 20 u. 37.; MAX (1975) 46-49; OOST (1964) 23-29. Bedenken erhebt STICKLER (2002) $76 \mathrm{f}$.

225 Vgl. HENNING (1999) 47 und bes. CLOVER (1978). Zu den Aniciern in Konstantinopel vgl. jetzt auch BEGASS (2018) 353-362, zu Anicius Olybrius bes. 355-357, der hiernach erst nach 455 Rom verlassen haben soll.

226 Am deutlichsten findet dies seinen Niederschlag in der Darstellung Prok. BV. 1,4,17ff.

227 Die Eheschließung wurde so auch tatsächlich vollzogen, jedoch erst Ende 456/Anfang 457 (nach CLOVER (1978)), nachdem die Verhandlungen mit Geiserich erfolgreich abgeschlossen werden konnten. Vgl. HENNING (1999) 47 f.; ferner NAGY (1990/1991) 90 und WIRTH (1986) 185-206, hier 204.

228 Vgl. Ioh. Ant. fr. 201 (wohl auf Prisk. fr. 30,1 zurückgehend); Euagr. Hist. eccl. 2,7; Theoph. a. m. 5947; Marcell. Com. s. a. 455 (= Chron min. II. 86) und bes. Prok. BV. 1,4,17 ff.; die rohen amourösen Begierden und das Intrigenspiel des Petronius Maximus, dem hier der Tod des Aëtius und Valentinians III. in einem bravourösen ,Schurkenstück' angelastet wird, entsprechen zum einen dem Bemühen, die Plünderung Roms durch die Vandalen erklärbar zu machen, zum anderen aber auch dem generell 
Von besonderer Wichtigkeit ist hierbei der Umstand, dass die stadtrömische Senatsaristokratie nicht geschlossen hinter Petronius Maximus stand. Es verwundert daher nicht, dass der neue Kaiser so schnell alle Unterstützung in Rom einbüßte. Offensichtlich ließ Petronius Maximus keine oder nur kaum Bereitschaft erkennen, die Interessen der stadtrömischen Häuser angemessen zu vertreten. ${ }^{229}$ Stattdessen handelte er allein zum eigenen Vorteil und dem seiner Nachkommenschaft. Es ist kaum nachzuvollziehen, wie es überhaupt möglich war, dass ein Mann, der auf eine jahrzehntelange Erfahrung am Hof, in der Reichsverwaltung und im Senat zurückblicken konnte, nun plötzlich so wenig politisches Feingespür an den Tag legte, dass ihn seine Handlungsweise selbst bei natürlichen Verbündeten diskreditieren musste. Nur auf einen Anflug von schierer Selbstüberschätzung oder maßlosen Ehrgeiz zu setzen, wie dies Seeck, Czúth und nachfolgend nicht wenige Althistoriker taten, ${ }^{230}$ ist sicher zu kurz gegriffen und verkennt einen ganz entscheidenden Wesenszug der Regierung des Petronius Maximus. So wie sich dies noch einschätzen lässt, waren Rom und die stadtrömische Senatsaristokratie nie die maßgebliche Machtbasis des Petronius Maximus und wurden von diesem daher eher weniger in seine Überlegungen einbezogen. Ein Indiz hierfür stellt die Münzprägung dar, die gänzlich auf einen Rom-Bezug verzichtet. Dagegen richtete sich das Augenmerk des Petronius Maximus viel stärker auf Gallien und die Westgoten-Frage. Damit trat der neue Kaiser weniger die Nachfolge Valentinians an, der sich verstärkt auf Rom und Italien konzentrierte, als vielmehr das politische Erbe, welches Fl. Aëtius ${ }^{231}$ oder auch Fl. Constantius $^{232}$, hinterlassen hatten. Die Nähe zur gallo-römischen Aristokratie und die Entfremdung mit Rom und seinen stadtrömischen Standesgenossen war hierbei sicher keine neuerliche Entwicklung, sondern ein Resultat der politischen Zusammenarbeit mit Aëtius ${ }^{233}$.

negativen Bild, welches Konstantinopel von Petronius Maximus ohnehin, gewiss auch durch Zutun des Anicius Olybrius, hatte; so auch SZIDAT (2010) 128.

229 Hierzu auch ANDERS (2010) 51f. und HENNING (1999) 118-120.

230 Vgl. SEECK (1920) 322f.; CZÚTH (1983) 254; ebenso u. a. noch STICKLER (2007b) 286: „Schon nach zwei Monaten bezahlte Petronius Maximus seinen übertriebenen Ehrgeiz mit dem Leben.“ Vgl. auch SZIDAT (2010) 234.

231 Nov. Val. 9 (24.6.440) drückt angesichts der Bedrohung durch die Vandalen sogar die Hoffnung einer baldigen Rückkehr des Aëtius aus Gallien aus. Im Jahr 452 als Attila in Italien einfiel, scheint Aëtius ebenfalls nicht präsent gewesen zu sein; Prosp. Tiro 1367 (s. a. 452) gibt für den wehrunfähigen Zustand Italiens sogar Aëtius die Schuld; vgl. STICKLER (2002) 145-150. Vom engen Verhältnis des Aëtius zur gallischen Senatsaristokratie zeugt am deutlichsten Sidonius Apollinaris, der Aëtius in höchsten Tönen pries und mit Verachtung auf Valentinian III. zurückblickte; so Sid. carm. 7,537-547 oder 7,356 - 363, bes. 359: Placidus [...] semivir amens; zur Formulierung vgl. STICKLER (2007b) 277. Zum Verhältnis des Aëtius zur gallischen Senatsaristokratie vgl. ANDERS (2010) 51 und HENNING (1999) 18 mit Anm. 15; ausführlich STICKLER (2002) 161-224 u. bes. 302f. und ZECCHINI (1994) 92-107.

232 Vgl. LÜTKENHAUS (1998) 38-51, 110 -129 u. 153; STROHEKER (ND 1970) 43-51, hier 50: „Durch sein Entgegenkommen konnte er den politischen Willen der gallischen Aristokratie mit den Zielen der Regierung in Ravenna [oder besser mit den eigenen Zielen] in Einklang halten.“

233 Zur Zusammenarbeit mit Aëtius vgl. STICKLER (2002) 80-83 u. 291-299. Vgl. hierzu Kap. 5.3. 
Um sich den Ansprüchen und dem Einfluss der stadtrömischen Senatsaristokratie zu entziehen, genügte es aber nicht, die gallische Senatsaristokratie der römischen entgegenzustellen. Auch eine räumliche Trennung wäre langfristig notwendig geworden. Dass eine Übersiedlung des Hofes von Rom zurück nach Ravenna beabsichtigt gewesen sein könnte, deutet möglicherweise die Wiederaufnahme der SolidiPrägungen in der ravennatischen Münze ${ }^{234}$ an. Die schwache Militärpräsenz in Rom, die während der vandalischen Invasion die Aufrechterhaltung der Ordnung und die Verteidigung der Stadt unmöglich machte, ließe sich durch den teilweisen Abzug der Hoftruppen nach Ravenna erklären. Überdies war zum Zeitpunkt der Plünderung Roms Majorian als comes domesticorum offenbar nicht mehr vor Ort. ${ }^{235}$ All dies spricht dafür, dass in den Jahren 455/456 die Bedeutung Ravennas als Machtzentrum wieder zunahm. Demnach ist es nicht undenkbar, dass die Machtverlagerung von Rom nach Ravenna bereits unter Petronius Maximus vorbereitet worden war. In der Tat muss sich dieser im Milieu des ravennatischen Hoflebens um einiges sicherer gefühlt haben als im Kreis der stadtrömischen Senatsaristokratie oder im Senat. Mit Ausnahme der zweimaligen Stadtpräfektur (420/421 und 439), bekleidete Petronius Maximus Hofämter, die eine mehrjährige Präsenz am ravennatischen Hof voraussetzten. ${ }^{236}$ Dagegen kann er wohl nur schwer als princeps senatus ${ }^{237}$ verstanden werden. Auch die ihm gewährten Ehrungen geben keinerlei Auskunft über ein besonders nahes Verhältnis zum Senat. So mangelt es gänzlich eines Verweises auf eine lange Tätigkeit im Senat, wie dies beispielsweise für Iulius Agrius Tarrutenius Marcianus ${ }^{238}$ bezeugt ist. Petronius Maximus stützte sich stattdessen wohl eher auf die verbliebenen Parteigänger des Aëtius, vor allem aber auf die gallo-römische Senatsaristokratie, und hoffte hieraus genug Stärke zu gewinnen, um Rom und seine senatorischen Häuser unter Kontrolle zu halten.

234 RIC 10, 2203. Unter Valentinian III. erfolgen die Goldprägungen ab 445 verstärkt in Rom; im Jahr 455 sind zehn von dreizehn Goldprägungen der stadtrömischen Münze zuzuordnen (RIC 10, 20382046 u. 2048) und nur eine eindeutig der ravennatischen (RIC 10, 2049). Von den drei bekannten SolidiPrägungen des Petronius Maximus werden eine in Ravenna (RIC 10, 2203) und zwei in Rom (RIC 10, 2201, 2202) herausgegeben. Vgl. SELLARS (2013) $724 \mathrm{f}$; BEIER (2002) 404 und VAGI (2000) $563 \mathrm{f}$.

235 Er ist zwar zwischen März 455 und Oktober 456 überhaupt nicht fassbar, erscheint aber dann in Ravenna und nimmt dort am 28. Dezember 457 den Augustus-Titel an (vgl. Sid. ep. 1,11). Bereits am 17. September 456 wurde Remistus, der Heerrmeister des Avitus, im Flottenstützpunkt Classis bei Ravenna ermordet, von wo aus auch die Rebellion gegen Avitus seinen Ausgang nahm. Vgl. ANDERS (2010) 102-109 und HENNING (1999) 134 in Ravenna als Residenz des Majorian.

236 Als tribunus et notarius und comes sacrarum largitionum (ca. 416-419) hielt sich Petronius Maximus am Hof des Honorius in Ravenna auf; als praeceptor Kaiser Valentinians III. wird er wohl zwischen 425 und 437 ebenfalls in Ravenna präsent gewesen sein; in der Funktion des PPO (433? und 439441) gleichermaßen.

237 So immer noch fälschlich angenommen u. a. von SZIDAT (2010) 127 Anm. 510; DEMANDT 2(2007) 189; PACK (1997) 400. Bedenken aufgrund mangelnder Belege erhob schon SIEBIGS (2010) 736 Anm. 53.

238 PLRE 2, 718f. (Agrius Tarrutenius Marcianus 20, PVR): CIL 6, 1735. Vgl. NIQUET (2000) 144 u. $160 \mathrm{f}$. mit Anm. 114. 
Dies war offensichtlich eine Fehleinschätzung. Die Kräfte, die die Anhängerschaft der theodosianischen Dynastie und der senatorischen Häuser Roms noch mobilisieren konnten, erwiesen sich für den neuen Herrscher als nicht beherrschbar. Die Eheverbindungen mit dem theodosianischen Kaiserhaus, die wohl auch die im Widerstreit befindlichen Fraktionen hätte einen sollen, wirkten sich, da dies mehr Feinde als Verbündete schuf, destruktiv aus. Seine Herrschaft doch noch durch die Erfolge in Gallien zu stabilisieren, sollte Petronius Maximus nicht mehr vergönnt sein. Die Zeit arbeitete zu seinen Ungunsten und bereits drei Monate nach seiner Inthronisierung hatte er jeglichen Rückhalt, den er noch in Rom besaß, verspielt. Als Geiserichs Flotte $^{239}$ Ende Mai an der Tibermündung gesichtet wurde, kollabierte das von Petronius Maximus geführte Regime.

Sidonius Apollinaris ließ das Ende von Petronius Maximus, der so lange hoch aufgestiegen und so schnell hinabgestürzt war, vor Serranus, einem ehemaligen Klienten des Petronius Maximus, geradezu zum ,Menetekel' werden. ${ }^{240}$ Die Worte mahnten noch fünfzehn Jahre später ${ }^{241}$ vor dem schrecklichen Beispiel, welches Petronius Maximus, der in seinem früheren Leben nahezu alles besessen hatte und dies gegen eine zwei Monate währende Herrschaft in Aufruhr eintauschte, ${ }^{242}$ abgab. Noch

239 Die Beweggründe für den Angriff Geiserichs auf Rom werden kontrovers diskutiert. Vgl. zusammenfassend in Auseinandersetzung mit älteren Forschungsmeinungen HENNING (1999) 21-27; aktuell zum Ereignisgeschehen vgl. VÖSSING (2014) 53-60; BÖRM (2013) 97-99; HEATHER 2(2010) 455-456; CASTRITIUS (2007) 104-107 oder SCHMIDT (2000) 200 f. Die Überlieferung, wonach Geiserich auf ein Hilfsgesuch der bedrängten Kaiserinwitwe Licinia Eudoxia in See gestochen sein soll (Prok. BV. 1,5), lässt sich wohl eher nicht als reale Gegebenheit oder maßgeblicher Grund annehmen; tatsächlich zeigt sich hier ein Erklärungsmuster, welches vor allem dazu dient, die prinzipielle Überlegenheit der Römer zu wahren, indem die ,Barbaren' als ins Reich gerufen präsentiert werden (vgl. auch Oros. 7,38,3f. zu Stilicho; u. a. Prok. BV.1,3,23-26: Bonifatius und die Vandalen; Ioh. Ant. fr. 199,2: Honoria und Attila; Paul. Diac. Hist. Lang. 2,59: Narses und die Langobarden); aktuell vgl. HEATHER (2011) 308f. und HOWE (2007) 232f. mit Anm. 13. Letztendlich steht auch fest, dass Licinia Eudoxia und ihre Töchter durch die vandalische Invasion keineswegs die Freiheit erhielten, sondern zu überaus wertvollen Geiseln für Geiserich wurden. Die Aussicht auf leichte Beute gegenüber einem Rom, welches keine Unterstützung vom Osten zu erwarten hatte und durch innere Wirren geschwächt war, sollte ausreichend Anreiz geboten haben. Die Annahme von WIRTH (1986), wonach Geiserich zum Anwalt des theodosianischen Kaiserhauses wurde, indem er der bedrängten Kaiserinwitwe zur Hilfe kam, ist wohl haltlos und kann kaum als Hauptanliegen Geiserichs verstanden werden. Vgl. zuletzt VÖSSING (2018) 77-89 und BÖRM (2013) 98.

240 Sid. ep. 2,13,4f. An dieser Stelle danke ich Herrn Prof. Dr. Timo Stickler für den Hinweis zur Quelle und die Einsichtnahme in ein Skript zu einem unpublizierten Vortrag zu Petronius Maximus.

241 Die Datierung ca. 469/470 folgt der Edition LOYEN (1970).

242 Sid. ep. 2,13,4: denique require in supradicto vitae prioris gratiam, potentiam, diuturnitatem, eque diverso principatus paulo amplius quam bimenstris originem, turbinem, finem: profecto invenies hominem beatiorem prius fuisfse quam beatissimus nominaretur; vgl. auch Sid. ep. 2,13,5: ipsam aulam turbulentissime rexit inter tumultus militum popularium, foederatorum [...]. Vgl. Hierzu jetzt auch MEURER (2019) $205 \mathrm{f}$. 
vor der Abenddämmerung, eingeschlossen in den Mauern des Palasts, ${ }^{243}$ soll Petronius Maximus, dem in seinem früheren Leben so vieles geglückt war, über sein Schicksal aufgestöhnt haben. ${ }^{244}$ Bewusst setzt Sidonius Apollinaris das senatorische Leben des Petronius Maximus, welches in voller Blüte stand, in ein antithetisches Verhältnis zu dessen glückloser Herrschaft und gab zu bedenken, dass das Geschäft des princeps und die Ruhe des Senators nicht in Einklang zu bringen seien. ${ }^{245}$

Als letzte kaiserliche Handlung soll Petronius Maximus Rom zur ,offenen Stadt erklärt haben. ${ }^{246}$ Damit wurde deutlich, dass er der kaiserlichen Verpflichtung zur cura gegenüber der Urbs aeterna und dem Imperium nicht mehr nachzukommen imstande war. ${ }^{247}$ Für Petronius Maximus war die Aufgabe des Herrschersitzes gleichbedeutend mit dem Ende seiner Herrschaft. Am 31. Mai 455 wurde er auf der Flucht ermordet. Sein Leichnam wurde von der aufgebrachten Menge in Stücke gerissen und in den Tiber geworfen. ${ }^{248}$ Abermals sind es die entscheidenden Akzeptanzgruppen, die der Herrschaft des Petronius Maximus ein Ende setzen. In diesem Fall sind die plebs urbana ${ }^{249}$, die Soldaten ${ }^{250}$ und der comitatus ${ }^{251}$ daran beteiligt. Dennoch ist auch die Rolle, die der Senat und die stadtrömische Senatsaristokratie hierbei spielten, alles andere als unwesentlich. Interne Streitigkeiten, Missgunst und Eifersüchteleien beherrschten das Handeln der stadtrömischen Senatsaristokratie. Statt geschlossen den äußeren Feinden entgegenzutreten, verharrte die Aristokratie

243 Sid. ep. 2,13,4: Palatinis liminibus inclusus; hier greift Sidonius Apollinaris auf das bekannte Bild des princeps clausus zurück und betont damit vor allem die Handlungsunfähigkeit und Hilflosigkeit des Petronius Maximus gegenüber den sich stellenden Herausforderungen und Problemen.

244 Sid. ep. 2,13,4: Igitur ille, cuius anterius epulae mores, pecuniae pompae, litterae, fasces, patrimonia, patrocinia florebant, [...] ante crepusculum ingemuit, quod ad vota pervenerat.

245 Sid. ep. 2,13,4: [...] pariter ire non posse negotium principis, et otium senatoris. Zur Bewertung der Herrschaft des Petronius Maximus durch Sidonius vgl. auch MEURER (2019) 205f. und HENNING (1999) 119f. Zum senatorischen otium-Ideal vgl. u. a. HEATHER (1998) 193-195 und MATTHEWS (1975) 1-12; ausführlich vgl. DEWAR (2014); ferner BÖHM (2014) 15-25 und HEISING (2014) 219-237.

246 Prok. BV. 1,5,4; Zon. 13,25. Vgl. u. a. Marcell. Com. s. a. 455 und Hyd. Lem. 162 (s. a. 455). Vgl. hierzu SZIDAT (2010) 227 und PACK (1997) 400.

247 Vgl. SZIDAT (2010) 227; Angesichts des Unvermögens des Kaisers, den Schutz der Stadt und seiner Untertanen zu gewährleisten, konnte dieser keine Gefolgschaft mehr erwarten und es entlud sich der ganze Volkszorn und die Wut der Soldaten an seiner Person.

248 Vgl. Prosp. Tiro 1375 (s. a. 455); Vic. Tonn. Chron. s. a. 455 (= Chron. min. II. 186) und Prok. BV.1,5,1f.

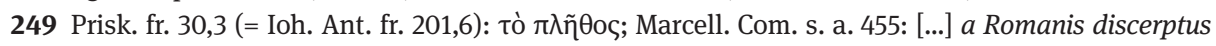
est; vgl. auch Paul. Diac. Hist. Rom. 14,6; Iord. Rom. 334.

250 Cassiod. Chron. 1262: a militibus; Iord. Get. 235f.: a quodam Urso, milite Romano, interemptus est. Vgl. HENNING (1999) 31 Anm. 21 u. 34 Anm. 39.

251 Sid. carm. 7,442f.: infidoque tibi Burgundio ductu extorquet trepidas mactandi principis iras; zur Diskussion steht, ob es sich hierbei um einen burgundischen Soldaten der Leibgarde des Petronius Maximus handelte. Vgl. KAUFMANN (1995) 140 mit Anm. 366. Diese Annahme ist sehr verlockend und würde - so sie denn zuträfe - unterstreichen, dass sich Petronius Maximus tatsächlich stärker auf die Unterstützung aus dem gallo-römischen Raum verlassen hatte bzw. direkt das Gefolge des Aëtius übernommen hatte; am ehesten wäre hier wohl an die Bucellarii zu denken. Vgl. aktuell MAIER (2005) 16 u. 43 f. Wie jedoch HENNING (1999) 34 Anm. 39 richtig anmerkt, ist dies nicht sicher. 


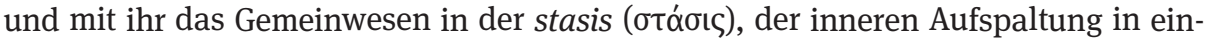
ander bekämpfende ,Fraktionen' ${ }^{652}$ Weder Petronius Maximus noch dem Senat gelang es, einen Ausgleich im consensus universorum herbeizuführen. Petronius Maximus mochte dies durch die Umstände seiner Machtergreifung und seines Herrschaftsstils verschuldet haben. Die stadtrömische Senatsaristokratie nahm die innere Destabilisierung für den Sturz des ungeliebten Herrschers aber ebenso ganz bewusst in Kauf.

Angesichts dessen ein „apolitisches Verhalten der Senatsaristokratie gegenüber den Sachen des Reiches“ anzunehmen, wie dies Czúth und Lucki vertraten, ${ }^{253}$ ist dennoch verfehlt. Letztendlich ist es doch gerade so, dass Petronius Maximus vor allem am Widerstand der senatorischen Häuser Roms scheiterte. Das Interesse von Teilen der Senatsaristokratie, den tyrannus zu stürzen, ließ sich gewiss mit der senatorischen Sorge um das Gemeinwesen in Einklang bringen. Bei dieser nach innen gerichteten Denkweise ist es jedoch nicht verwunderlich, dass der Blick auf die akuten militärischen Bedrohungen dermaßen verstellt war. Weder Marcian noch die stadtrömische Senatsaristokratie waren bereit, ihren Widerstand aufzugeben und sich mit Petronius Maximus zu arrangieren, der paradoxerweise tatsächlich bereit gewesen war, die militärischen Probleme des Weströmischen Reichs anzugehen. Das Versagen aller Instanzen, des Kaisers, des Hofs, der Senatsaristokratie, des Senats und des Heeres führte zur Katastrophe. ${ }^{254}$

252 Hier ist an Anicius Olybrius und auch die senatorischen Unterstützer der Kaiserinwitwe (u. a. auch Majorian) zu denken. Präzise lassen sich diese ,Fraktionen‘ allerdings nicht bestimmen. Vgl. BÖRM (2013) 145 und zur Anwendung der Begrifflichkeit auf spätantike Verhältnisse vgl. DEMANDT (2013c) $324-337$ bes. $326-331$ [1996].

253 CZÚTH (1983) 258 und LUCKI (1960) 89-98, hier 96.

254 HENNING (1999) 213 nennt dies ein „selbstverschuldete(s) Desaster“, womit er Recht hat. 